\title{
A transcriptomic analysis of gene expression in the venom gland of the snake Bothrops alternatus (urutu)
}

\author{
Kiara C Cardoso ${ }^{1}$, Márcio J Da Silva², Gustavo GL Costa², Tatiana T Torres², Luiz Eduardo V Del Bem², \\ Ramon O Vidal ${ }^{3}$, Marcelo Menossi ${ }^{3}$, Stephen Hyslop ${ }^{1 *}$
}

\begin{abstract}
Background: The genus Bothrops is widespread throughout Central and South America and is the principal cause of snakebite in these regions. Transcriptomic and proteomic studies have examined the venom composition of several species in this genus, but many others remain to be studied. In this work, we used a transcriptomic approach to examine the venom gland genes of Bothrops alternatus, a clinically important species found in southeastern and southern Brazil, Uruguay, northern Argentina and eastern Paraguay.
\end{abstract}

Results: A cDNA library of 5,350 expressed sequence tags (ESTs) was produced and assembled into 838 contigs and 4512 singletons. BLAST searches of relevant databases showed 30\% hits and 70\% no-hits, with toxin-related transcripts accounting for $23 \%$ and $78 \%$ of the total transcripts and hits, respectively. Gene ontology analysis identified non-toxin genes related to general metabolism, transcription and translation, processing and sorting, (polypeptide) degradation, structural functions and cell regulation. The major groups of toxin transcripts identified were metalloproteinases (81\%), bradykinin-potentiating peptides/C-type natriuretic peptides (8.8\%), phospholipases $\mathrm{A}_{2}(5.6 \%)$, serine proteinases (1.9\%) and C-type lectins (1.5\%). Metalloproteinases were almost exclusively type PIII proteins, with few type PII and no type PI proteins. Phospholipases $A_{2}$ were essentially acidic; no basic PLA $A_{2}$ were detected. Minor toxin transcripts were related to L-amino acid oxidase, cysteine-rich secretory proteins, dipeptidylpeptidase IV, hyaluronidase, three-finger toxins and ohanin. Two non-toxic proteins, thioredoxin and double-specificity phosphatase Dusp6, showed high sequence identity to similar proteins from other snakes. In addition to the above features, single-nucleotide polymorphisms, microsatellites, transposable elements and inverted repeats that could contribute to toxin diversity were observed.

Conclusions: Bothrops alternatus venom gland contains the major toxin classes described for other Bothrops venoms based on trancriptomic and proteomic studies. The predominance of type PIII metalloproteinases agrees with the well-known hemorrhagic activity of this venom, whereas the lower content of serine proteases and C-type lectins could contribute to less marked coagulopathy following envenoming by this species. The lack of basic PLA $A_{2}$ agrees with the lower myotoxicity of this venom compared to other Bothrops species with these toxins. Together, these results contribute to our understanding of the physiopathology of envenoming by this species.

\section{Background}

Studies of the global composition of snake venoms have advanced dramatically in recent years with the introduction of transcriptomic and proteomic approaches for

\footnotetext{
* Correspondence: hyslop@fcm.unicamp.br

'Departamento de Farmacologia, Faculdade de Ciências Médicas, Universidade Estadual de Campinas (UNICAMP), CP 6111, 13083-970, Campinas, SP, Brazil

Full list of author information is available at the end of the article
}

analyzing venom gland gene expression and venom composition [1-3]. The introduction of these two major fields in toxinology has created new perspectives for identifying novel molecules for drug discovery $[4,5]$ and for improving antivenom development and the clinical treatment of snakebite [6-8]. A combination of these two approaches can be particularly useful in providing a more comprehensive understanding of venom composition [3,9-12].

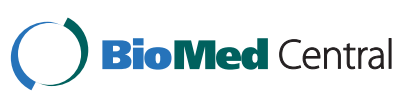


Detailed transcriptomic studies of snake venom glands began with the report of Junqueira-de-Azevedo and Ho [13] who analyzed expressed sequence tags (ESTs) from the venom gland of the Brazilian pitviper Bothrops insularis, a species endemic to the island of Queimada Grande off the coast of the State of São Paulo in southeastern Brazil. Since then, venom gland transcriptomes have been reported for various other South American venomous snakes, including Bothrops species [11,14-16], Crotalus durissus collilineatus (South American rattlesnake) [17], Lachesis muta (bushmaster) [18], Micrurus corallinus (coral snake) [19] and the colubrid Philodryas olfersii [20].

The genus Bothrops is responsible for most cases of snakebite throughout Latin America [21] and in Brazil accounts for $80-90 \%$ of bites by venomous snakes. Envenoming by Bothrops species results in extensive local effects, including pain, edema, inflammation, hemorrhage and necrosis [22-24], as well as systemic actions that include coagulopathy, internal hemorrhage, circulatory shock and acute renal failure [21,25-28]. These actions are mediated by a variety of venom components, with the most extensively studied being (hemorrhagic) metalloproteinases [29] and myotoxic phospholipases $A_{2}$ $\left(\mathrm{PLA}_{2}\right)[23,30,31]$.

Bothrops alternatus occurs in southeastern and southern Brazil, Uruguay, central and northern Argentina and south-eastern and southern Paraguay [32]. This species is an important cause of snakebite, although the prevalence of bites varies considerably throughout its geographic distribution depending on the regional human and snake population densities and the presence of more abundant species such as Bothrops jararaca, the major cause of snakebite in southeastern Brazil. Thus, for example, notifications of bites by Brazilian Bothrops spp. received by the Instituto Butantan from 1902-1945 ( $\mathrm{n}=4,881$ ) suggest that B. alternatus accounts for $\sim 6 \%$ of bites by this genus [33]. In contrast, in a more recent series of 3,139 cases attended at the Hospital Vital Brazil, Instituto Butantan in São Paulo, from 1981-1990, only two $(0.14 \%)$ of the 1,412 cases in which the Bothrops species was identified were caused by $B$. alternatus compared to $1,376(97.5 \%)$ by $B$. jararaca [34]. In regions where $B$. alternatus is more abundant or predominates (southern Brazil, Uruguay and parts of Argentina), this species contributes to much a greater proportion of snakebites, e.g., $18 \%$ in Argentina, but may be much higher locally ( $\geq 60 \%$ of snakebites in the Argentinian province of Corrientes) [35].

Bothrops alternatus produces clinical manifestations characteristic of this genus [21,28]. In a series of 32 cases involving this species [36], most of the patients (74.2\%) were $15-49$ years old and were bitten in the lower limbs (84.3\%). All patients developed local pain, edema and most $(31 ; 96.9 \%)$ had incoagulable blood, 13 (40.6\%) developed hemorrhage, 7 (21.9\%) had blisters and $3(9.4 \%)$ showed necrosis; there were no fatalities. In addition, renal failure has been observed after bites by this species in Uruguay [37]. The administration of antivenom (produced by the Instituto Nacional de Producción de Biológicos - INPB in Argentina and the Instituto Butantan, Fundação Ezequiel Dias or Instituto Vital Brazil in Brazil) is the standard treatment for envenoming by $B$. alternatus. These antivenoms may be bivalent (raised against $B$. alternatus and B. neuwiedii in Argentina) or poplyvalent (raised against the clinically most relevant Bothrops species in Argentina and Brazil $B$. alternatus, B. jararaca, B. jararacussu, B. neuwiedi and $B$. moojeni) $[38,39]$. In the case series studied by Bauab et al. [36], a median of $40 \mathrm{ml}$ of antivenom (four $10 \mathrm{ml}$ ampoules) was administered.

Although $B$. alternatus venom contains a variety of enzymatic and biological activities, relatively few of the venom proteins involved have been purified and characterized, with most investigations having dealt with metalloproteinases and disintegrins [40-50], PLA 2 [51-55], coagulant enzymes [56-58], L-amino acid oxidase (LAO) [59] and phosphodiesterase [60]. Despite these investigations, the venom of $B$. alternatus is still less understood than those of other Bothrops species such as $B$. jararaca and B. jararacussu. In order to obtain a more comprehensive understanding of the toxinology of this species, we have used a transcriptomic approach to examine venom gland gene expression in $B$. alternatus and compared the results with those for other members of this genus.

\section{Methods}

\section{Venom glands and RNA isolation}

Venom glands from three adult $B$. alternatus snakes were obtained three days after venom extraction. The choice of this interval was based essentially on other studies $[16,17,61,62]$ that used this period, although intervals of two [14] and four [11,13] days post-milking have also been used for Bothrops species. The choice of a 2-4 day post-milking interval prior to gland removal is partly based on studies of venom mRNA and protein synthesis in snake venom glands that show maximal production 3-8 days post-milking [reviewed in [63]], and partly on histological and functional studies in B. jararacussu [64] and B. jararaca [65], respectively, showing that changes in gland epithelial morphology and venom production peak around four days post-milking.

Each pair of venom glands was homogenized in liquid nitrogen and total RNA was extracted with TRIzol reagent (Invitrogen, UK), according to the manufacturer's instructions. Three cDNA libraries (one from each snake) were independently constructed with 
CloneMiner cDNA library construction kits (Invitrogen, UK), according to the manufacturer's instructions. The cDNA libraries were processed and analyzed using an in-house bioinformatics pipeline, with all annotations being done manually (contig by contig and singlet by singlet) for each library. The production of three independent libraries meant that it was possible to undertake detailed analyses of SNPs, microsatellites and inversions not generally done for Bothrops species since in most studies the venom glands of different snakes are usually combined into a single pool for mRNA extraction, with a subsequent loss of information.

This work was approved by the institutional Committee for Ethics in Animal Experimentation (CEEA/UNICAMP, protocol no. 864-1) and was done according to the ethical guidelines of the Brazilian Society of Laboratory Animal Science (SBCAL, formerly the Brazilian College for Animal Experimentation - COBEA).

\section{Sequencing}

The cDNA libraries were sequenced using BigDye terminator 3.0 kits and an automated DNA capillary sequencer (ABI PRISM 3700 DNA Analyzer, Applied Biosystems, Foster City, CA, USA). All of the cDNA sequences were 5 ' sequenced using the primer $\mathrm{M} 13 \mathrm{~F}$ (5'-TGTAAAACGACGGCCAGT-3').

\section{Clusterization, assembly and identification of Bothrops alternatus expressed-sequence tags}

The Phred program [66] was used to obtain sequences and quality files from chromatograms obtained from expressed-sequence tag (EST) sequencing. The EST cleaning pipeline described by Baudet and Dias [67] was then used to pre-process the ESTs and prepare the sequences for assembly. This pipeline removes sequences with plasmid similarity, polyA/polyT regions, low base quality and slippage signals. Sequences $<100$ bp long after cleaning were discarded. CAP3 software [68] was used to cluster and assemble the clean sequences into contigs and singlets (unisequences). For assembly, an overlap of $100 \mathrm{bp}$ and an identity of at least $95 \%$ were used as criteria to detect pairwise similarities.

\section{Annotation of Bothrops alternatus ESTs}

After clustering and assembly, a BLAST search was done to identify similarities between the ESTs and sequences deposited in public databases. All of the sequences were aligned against the GenBank non-redundant $(\mathrm{nr})$ protein database using BLASTX and BLASTN [69] with an E-value cut-off of 1e-5. The B. alternatus ESTs were also screened against two locally generated sequence databases, SerpP and SerpN, that included all snake protein and nucleotide sequences from GenBank, respectively. In addition, the ESTs were compared with the complete genome of the lizard Anolis carolinensis (http://genome.ucsc.edu/cgi-bin/hgGateway?db=anoCar1). Gene Ontology annotation was done with Blast2GO [70] using GO-slim terms. The uncharacterized ESTs were examined for the presence of a signal peptide by using SignalP 3.0 software (http://www.cbs.dtu.dk/ services/SignalP/).

\section{Sequence alignments}

Sequence alignments for selected proteins were done with the program ClustalW [71].

\section{Single nucleotide polymorphisms}

The software QualitySNP [72] was used to identify single-nucleotide polymorphisms (SNPs). Non-synonymous and synonymous SNPs (nsSNPs and sSNPs, respectively) were identified by detecting open-reading frames (ORFs) of contigs with SNPs using the FASTA algorithm run against the 2008 version of UniProt [73]. The possibility of SNPs arising from artifacts during DNA sequencing was minimized by the fact that the cDNA libraries were prepared independently from three snakes and that we used consensus sequences from contigs with at least three reads from separate sequencing plates for which the cDNA was prepared and the reactions run on different days. These procedures considerably reduced the possiblity of artifacts derived from DNA sequencing and strengthened our conclusions regarding the presence of SNPs.

\section{Identification of transposable elements and long inverted repeats}

Alignment of the unisequences to repetitive elements in RepBase release 14.08 [74] was done with BLASTN that was automated using in-house Perl scripts (available upon request). The E-value cut-off was set at $1 \times 10^{-10}$ and only alignments of at least $50 \mathrm{bp}$ were considered for unisequences. In addition, the alignments with database sequences had to show $>80 \%$ identity over at least $10 \%$ of their lengths. To identify possible functional integrations of transposable elements (TEs) into host genes, we searched for chimeric transcripts between TEs and protein-coding genes. Unisequences that aligned with a TE in the database over $10 \%$ to $90 \%$ of their sequence were used to match the sequence back to the corresponding host gene by masking the element in the sequence and querying the NCBI nr nucleotide database. For tBLASTX remote searches, a minimum of $50 \%$ of the sequence was required to be involved in the best hit, with at least $70 \%$ identity.

Additional repeated elements that were not present in RepBase were observed in some unisequences. These novel elements were identified using the palindrome 
program in the EMBOSS package [75]. Unisequences that contained inverted repeats were identified by aligning each transcript against itself using BLASTN (E-value cut-off of 1e-5) and then inspected visually to check for alignments in opposite strands. The upper limit for mismatches between the two repeated segments was $10 \%$.

\section{Comparison of the B. alternatus EST library with other \\ Bothrops species}

The pattern of gene expression in B. alternatus venom gland was compared with EST data for other Bothrops species (B. atrox [16], B. insularis [11,13], B. jararaca [15] and B. jararacussu [14]) available in public databases, and with the major toxin classes detected by proteomic analyses of Bothrops venoms. In this comparison and in the description of the different toxin groups discussed below, the relative percentages of the venom gland EST categories were calculated as a percentage of the overall (total) number of all ESTs identified, whereas the relative percentages of the ESTs related to specific toxin groups was calculated based on the total number of toxin ESTs identified.

\section{Results and Discussion}

\section{Venom gland EST database}

cDNA libraries were generated from three pairs of $B$. alternatus venom glands and analyzed using the pipeline shown in Figure 1. A total of 5,350 valid unisequences was obtained by single-pass sequencing and, after trimming, the lengths of the sequences ranged from $100 \mathrm{bp}$ to 848 bp (mean: 562 bp) (Figure 2). The ESTs were assembled into 838 contigs and 4512 singletons. Thirty percent of the sequences $(1,605$ ESTs) were hits, of which 1,245 (23\% of total ESTs and $\sim 78 \%$ of hits) were related to toxins; the remaining $70 \%(3,745 \mathrm{ESTs})$ were

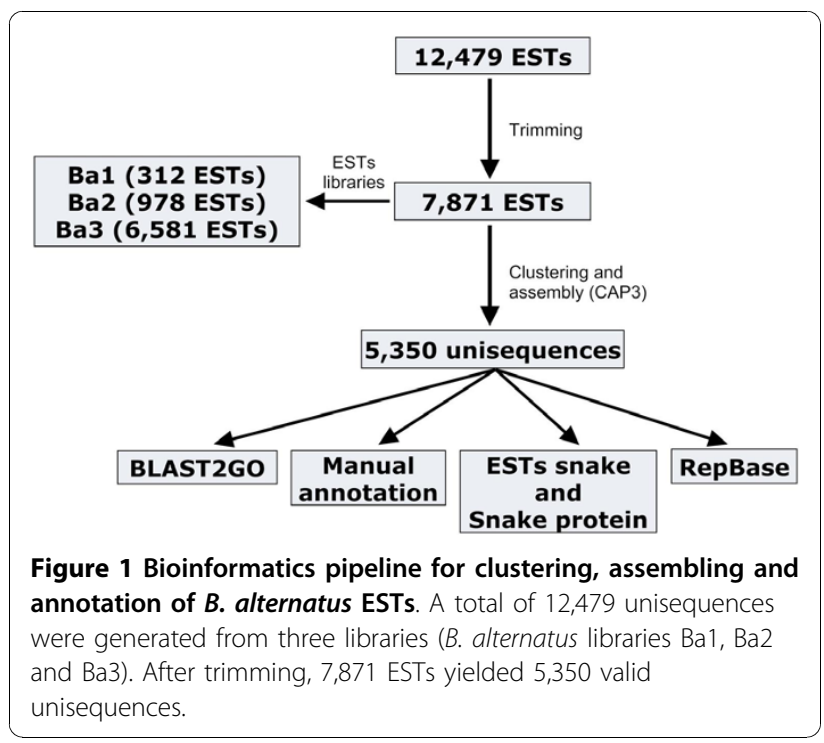

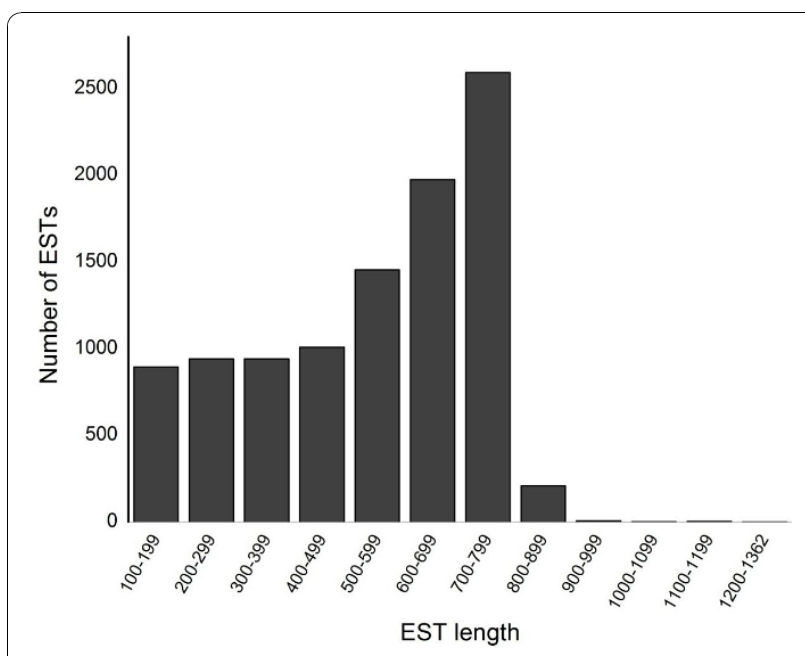

Figure 2 Size distribution of $B$. alternatus venom gland ESTs. Most of the 5,350 ESTs were 500-800 bp in length.

no-hits. Figure 3 shows the proportion of hits and nohits for selected databases. The proportion of hits was greater against the GenBank and SerpN nucleotide databases compared to the corresponding protein databases. There was a particularly low number of hits in SerpP, which likely reflects the limited number of non-venom snake protein sequences available in public databases.

SignalP analysis identified 147 ESTs with signal peptides, 62 of which were related to snake toxins (37 for $\mathrm{PLA}_{2}, 7$ for metalloproteinases, 6 for proteins related to platelet glycoprotein $1 \beta$ binding protein, 6 for proteins related to ACF $1 / 2 \beta$-chain, 4 for serine proteinases, and 1 each for disintegrins and bradykinin-potentiating peptides or BPPs), 50 were for other proteins and 35 were for unknown proteins.

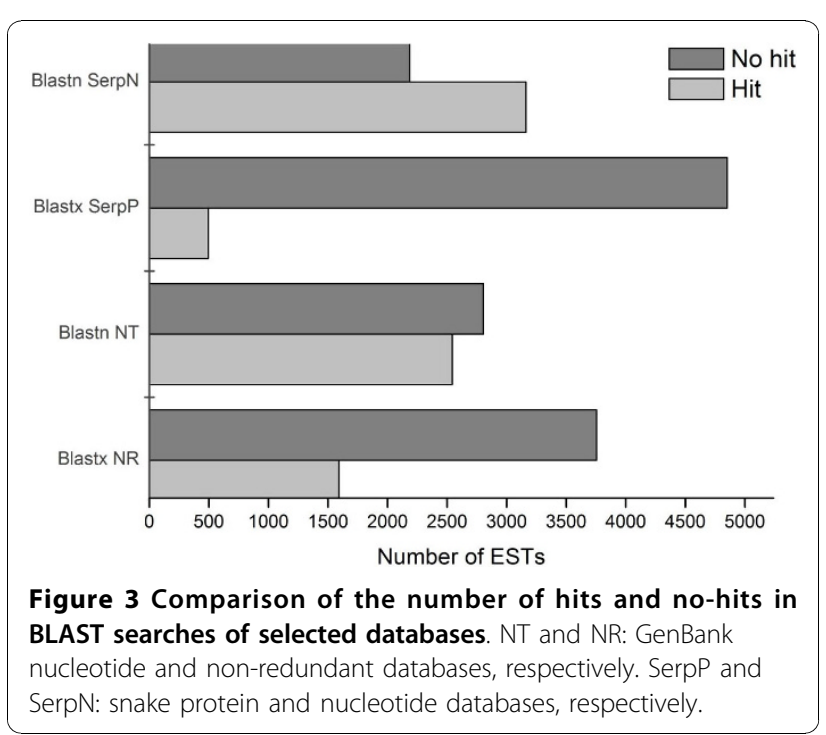


All of the ESTs were deposited in the dbEST division of GenBank (accession numbers GW575430 to GW583300).

\section{Gene ontology (GO)}

A global GO analysis [70] of unisequences in relation to molecular function revealed that the largest number of transcripts was related to protein binding, followed by peptidase and transferase activities, calcium-binding, enzyme regulation, nucleic acid binding, structural protein and transporter activities, lipid binding, and transcriptional regulation (Figure 4). Analysis of the biological processes revealed two major groups arbitrarily defined as those with $>100$ ESTs and those with $\leq 100$ ESTs. The former contained genes related to stress, responses to external stimuli, development, symbiosis, cell differentiation, DNA metabolism, cell death and signal transduction, whereas the latter consisted of genes related to catabolism, precursor biosynthesis, translation, protein modification, transcription, lipid metabolism, protein and ion transport, cytoskeletal organization, cell proliferation and cell cycle (Figure 5). The biological processes identified here generally agreed with the broad categories (general metabolism, transcription and translation, processing and sorting, (polypeptide) degradation, structural functions and cell regulation) reported for other Bothrops species [11,13-16] and L. muta [18].

\section{Selected venom gland proteins}

\section{Venom gland receptors}

We detected one transcript coding for a protein similar to $\alpha_{1 \mathrm{D}}$-adrenoceptor from $B$. jararaca. Since $\alpha$ - and $\beta$-adrenergic mechanisms have an important role in venom production in $B$. jararaca [76-78], principally through receptors structurally related to $\alpha_{1 D^{-}}$and $\alpha_{1 \mathrm{~B}}$-adrenoceptors [78], a similar regulatory mechanism mediated by these receptors probably also occurs in B. alternatus. Another receptor identified was vascular endothelin type $\mathrm{A}\left(\mathrm{ET}_{\mathrm{A}}\right)$ receptor (one singlet). This receptor mediates the vasoconstrictor activity of the endothelin family of peptides in B. jararaca aorta [79] and could be important in the regulation of vascular tone in blood vessels irrigating the venom gland.

A contig was identified for a calglandulin-like EF-hand protein. Venom gland calglandulin, initially identified in B. insularis based on an EST analysis of this venom gland [13] and subsequently cloned and expressed from this species [80] (also detected in elapid venom glands $[9,81])$, is a $\mathrm{Ca}^{2+}$-binding protein structurally similar to calmodulin and troponin $\mathrm{C}$. This protein, which is venom gland-specific (not found in other snake organs or venom) [80], may have a role in the transport and secretion of venom toxins, in addition to possibly acting as an intracellular $\mathrm{Ca}^{2+}$-chelator to regulate toxin activity.

\section{Molecular Functions}

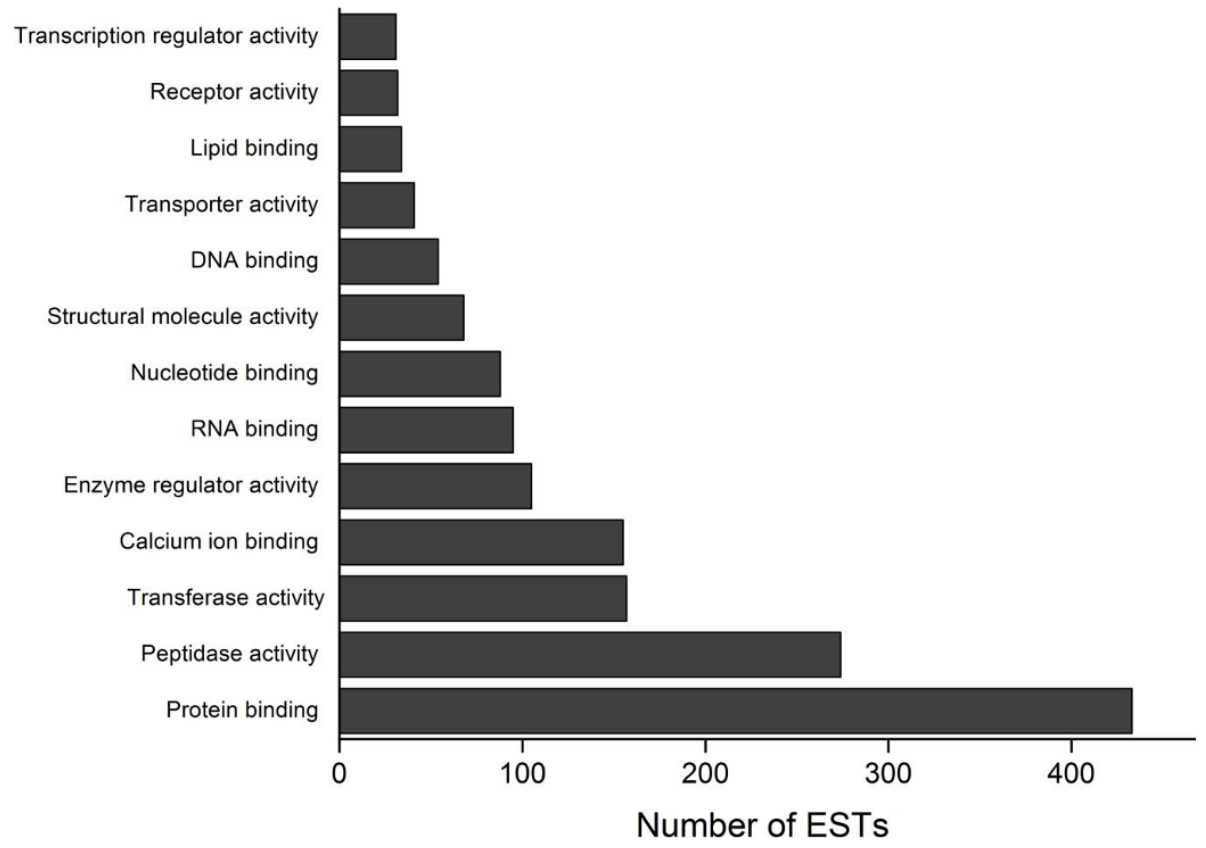

Figure 4 Molecular functions identified by Gene Ontology (GO) analysis of $B$. alternatus venom gland ESTs. The X-axis shows the number of ESTs and the Y-axis the GO terms. 


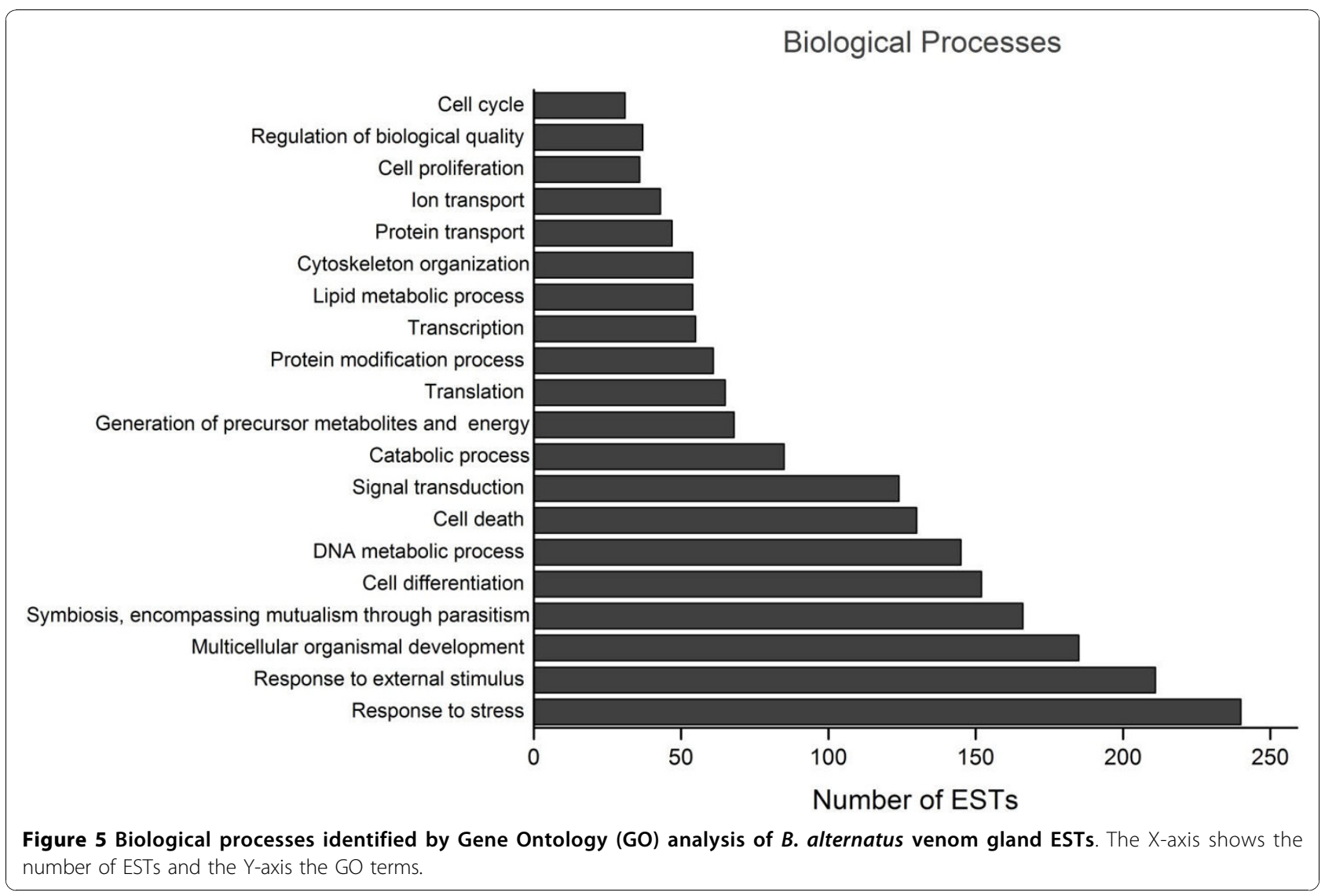

\section{Dusp6}

Dual specificity phosphatases (Dusp) have important functions in embryogenesis, cell growth and immune responses by acting as negative feedback regulators of mitogen-activated protein kinases (MAPK) [82]. DUSP6 has an important role in snake embryogenesis, with high gene expression in the anterior part of the presomitic mesoderm [83,84]. This protein has not previously been detected in venom gland transcriptomes or in analyses of venom composition. We detected a partial sequence for DUSP6 protein that shared similarity with the corresponding protein from Pantherophis guttatus (corn snake; accession number ABW82165) (Figure 6). The role of DUSP6 in the venom gland is unclear but may be related to development of the gland secretory epithelium and venom production.

\section{Thioredoxin}

Thioredoxin ( $\operatorname{Trx})$ is a protein with a variety of activities, including roles in DNA synthesis, protein disulfide bond reduction and the degradation of $\mathrm{H}_{2} \mathrm{O}_{2}$ that may be related to protection against oxidative stress and the induction of apoptosis [85]. Thioredoxin participates in redox reactions through the reversible oxidation of its active center dithiol to a disulfide, thereby catalyzing dithiol-disulfide exchange reactions; the reduction of the active site disulfide of oxidized Trx to regenerate the dithiol of reduced Trx is catalyzed by thioredoxin reductase, a selenium-containing flavoprotein [86]. Trx is also involved in the reversible S-nitrosylation of cysteine residues in target proteins, an important step in signaling by intracellular nitric oxide (NO). We found a protein sequence in the $B$. alternatus transcriptome that was related to Trx previously identified in venom gland cDNA from O. hannah (accession number AAK09384) (Figure 7). The function of Trx in venom glands is unknown, but it may be involved in protecting epithelial secretory cells of the gland from oxidative stress and death (by necrosis or apoptosis), particularly since venom components such as LAO can cause cell death through the formation of $\mathrm{H}_{2} \mathrm{O}_{2}[87,88]$.

\section{Venom components identified by ESTs}

Figure 8 summarizes the venom components detected based on EST analysis. The major classes detected were metalloproteinases/disintegrins, $\mathrm{BPP} / \mathrm{C}$-type natriuretic peptide $(\mathrm{CNP})$ precursors, $\mathrm{PLA}_{2}$, serine proteinases and C-type lectins. Genes expressed in lower abundance included cysteine-rich secretory proteins (CRISPs), taicatoxin-like protein, prothrombin activator, a catrocollastatin precursor and dipeptidylpeptidase IV (DPP IV). 


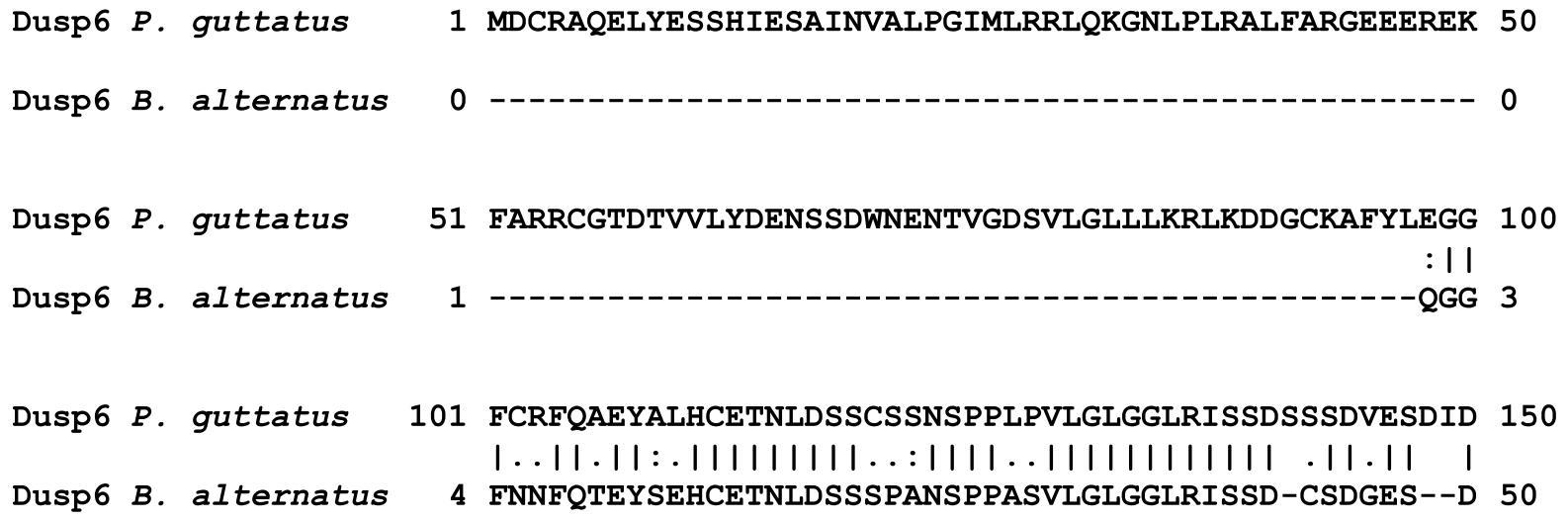

Dusp6 $P$. guttatus

Dusp6 B. alternatus
151 RDPNSATDSDGSPLSNNQPSFPVEILPYLYLGCAKDSTNLDVLEEFGIKY 200 $|:|:|||:|||||:|||||:|||:|||||||||||||:||||| .::||||$ 51 REPSSATESDGSPIPNNQPAFPVQILPYLYLGCAKDSSNLDVLGKYGIKY 100
Dusp6 $P$. guttatus

Dusp6 B. alternatus

Dusp6 $P$. guttatus

Dusp6 B. alternatus
201 ILNVTPNLPNLFENAGEFKYKQIPISDHWSQNLSQFFPEAISFIDEARGK 250

||||||||||$:||:|||||||||||||||||||||||||||:||||||$.

101 ILNVTPNLPNMFEHDGEFKYKQIPISDHWSQNLSQFFPEAIAFIDEARSK 150

Figure 6 Amino acid sequence alignment of $\boldsymbol{B}$. alternatus Dusp6 with that of Pantherophis guttatus (corn snake). The proteins showed greater similarity in the second half of their sequences. Insertions or deletions are represented by gaps (-), vertical bars (|) indicate identical residues, two dots (:) indicate strongly similar residues and one dot (.) indicates weakly similar residues.

\section{Major toxin classes}

\section{Metalloproteinases/disintegrins}

Bothrops venoms are rich in a variety of snake venom metalloproteinases (SVMPs) that contribute to local and systemic bleeding after envenoming $[21,28,29]$. SVMPs are currently classified in three major classes (PI, PII and PIII, with the latter two containing five and four subclasses, respectively) [89], with PIII metalloproteinases being particularly abundant and extensively studied in Bothrops venoms. Metalloproteinases were the most abundant venom components in B. alternatus venom gland (Figure 8) and were almost exclusively class PIII proteins. SVMPs accounted for 1010 ESTs that were grouped into 22 contigs, the most abundant of which were related to jararhagin from $B$. jararaca, Russell's viper (Vipera russelli) venom factor $\times$ heavy chain (RVV-X) and hemorrhagic factor 3 (HF3), also from B. jararaca (all class PIII proteins) (Figure 9). Hits were also obtained for Bothrops metalloproteinases such as berythactivase from $B$. erythromelas, bothropasin from $B$. jararaca and metalloproteinases II (Bojumet II) and III (Bojumet III) from B. jararacussu. There was a low number of transcripts for class PII proteins, including one transcript coding for contortrostatin and one contig related to insularinase. No class PI SVMPs were detected. The overwhelming abundance of transcripts for class PIII SVMPs (with few PII and no PI SVMPs) observed here agrees well with the results of a proteomic analysis of this venom in which only class PIII SVMPs were detected [90]. Our finding of transcripts related to jararhagin and berythactivase also agrees with these authors who detected proteins related to these two SVMPs in B. alternatus venom.

In agreement with the abundance of SVMP transcripts, two PIII metalloproteinases have been isolated and characterized from this venom. Souza et al. [40] reported the characterization of a $55 \mathrm{kDa}$ PIII metalloproteinase (alternagin) from Brazilian B. alternatus venom that can undergo autolysis to release a $28 \mathrm{kDa}$ ECD-disintegrinlike cysteine-rich domain (alternagin-C). Alternagin inhibits the binding of K562 cells to collagen by selectively blocking $\alpha_{2} \beta_{1}$ integrin, in a manner similar to jararhagin 


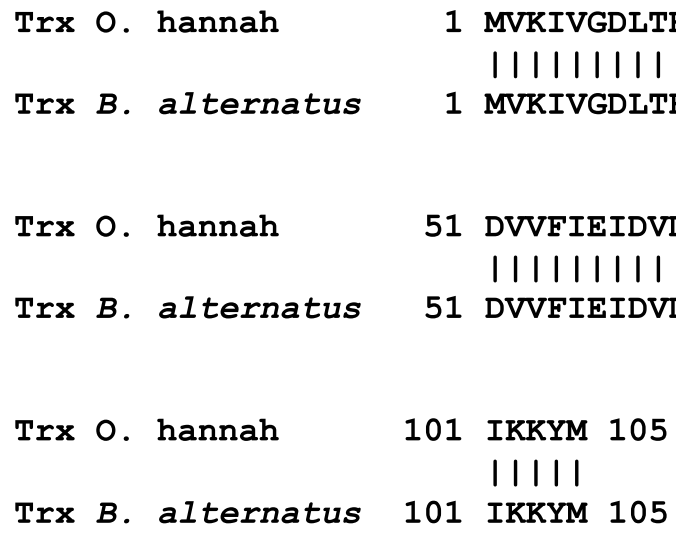

Figure 7 Amino acid sequence alignment of thioredoxin (Trx) from B. alternatus and $\boldsymbol{O}$. hannah. The sequences deduced from venom gland CDNA were identical.

from $B$. jararaca venom; this inhibitory action is apparently mediated by alternagin-C. Subsequently, Gay et al. $[44,45]$ also isolated alternagin (which they termed balteragin) from Argentine B. alternatus. This protein causes edema, hemorrhage and necrosis when administered intramuscularly in mice, and systemic hemorrhage, primarily in the lungs, kidneys and liver, when administered intravenously. Cominetti et al. [42] described the characterization of a $130 \mathrm{kDa}$ dimeric PIII metalloproteinase/RDG-disintegrin (BaG; monomeric form $=55 \mathrm{kDa}$ ) from Brazilian B. alternatus venom. This enzyme, which accounts for at least $0.2 \%$ of venom protein, inhibits
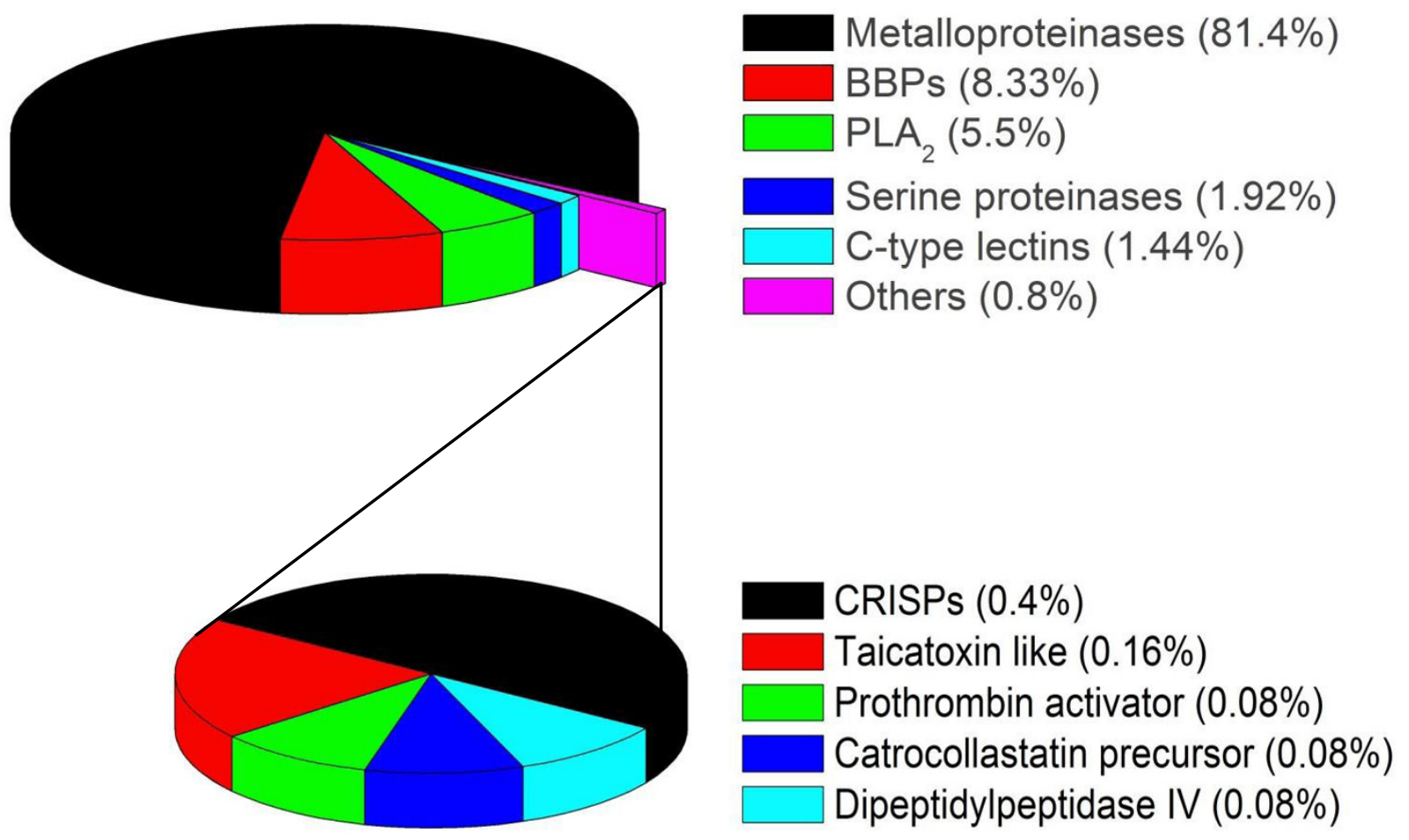

Figure 8 Principal toxin classes in the $\boldsymbol{B}$. alternatus venom gland EST library. The upper pie chart shows the major toxin classes detected and the lower pie chart shows the minor components (part of the "Others" group in the upper panel). The percentages indicate the abundance of each class relative to the total number of toxin-related ESTs in the library. BLAST only against nr hits with protein. 


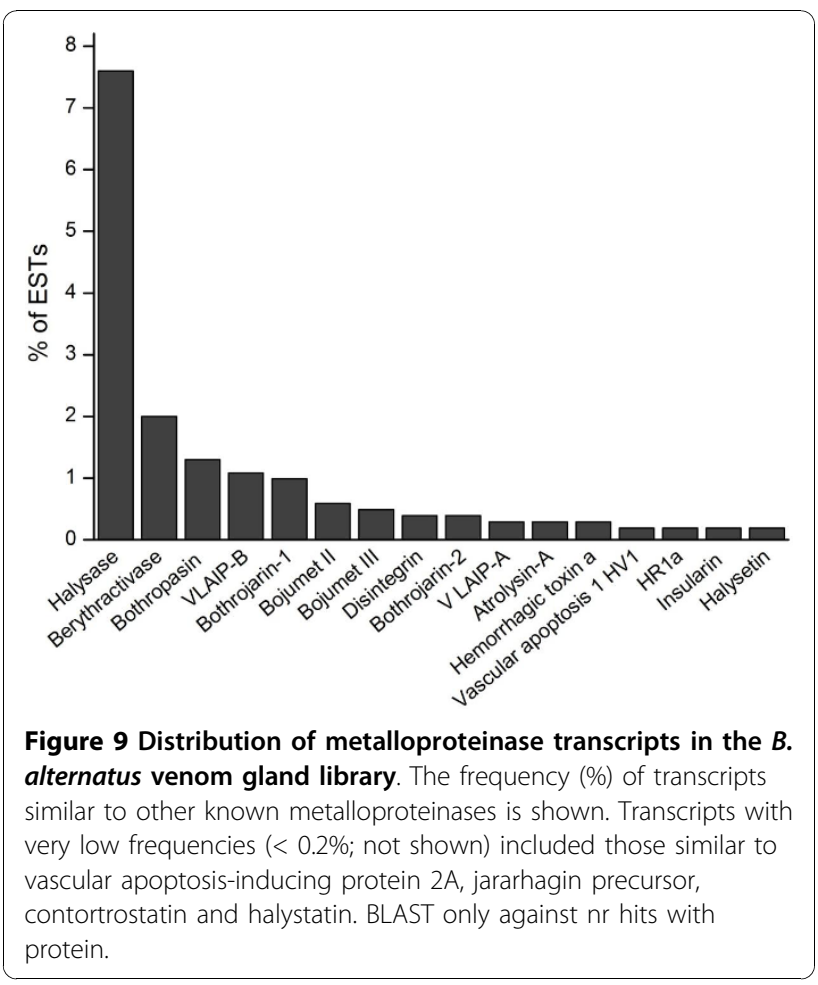

ADP-induced platelet aggregation via a mechanism independent of its enzymatic activity. BaG also blocks the adhesion of K562 cells to fibronectin (and detaches cells previously adhered to this protein), a phenomenon mediated by binding to $\alpha_{5} \beta_{1}$ integrin, but has no effect on the adhesion of these cells to collagen type I (mediated by $\alpha_{2} \beta_{1}$ integrin).

The processing of PII and PIII SVMPs gives rise to RDG-disintegrins and ECD-disintegrin-like cysteine-rich (DC) domains, respectively, that exert a variety of biological activities through interaction with cell surface integrins [89]. In the B. alternatus ESTs, there were four ESTs coding for disintegrins, and at least three disintegrins were identified in a proteomic analysis of this venom [90]. As indicated above, autolysis of alternagin gives rise to alternagin- $C$, an ECD-disintegrin-like cysteine-rich domain [40]. Alternagin- $C$ exerts a variety of activities, including the induction of neutrophil migration via integrin signaling [41], stimulation of human umbilical vein endothelial cell migration $[43,46]$ and modulation of angiogenesis in vitro and in vivo [47], but has a limited beneficial effect on muscle regeneration [48]. More recently, another disintegrin (DisBa-01) identified in a cDNA library from $B$. alternatus venom gland, has been shown to inhibit angiogenesis and melanoma mestastasis by interacting with $\alpha_{v} \beta_{3}$ integrin [49] and prevents platelet adhesion to fibrinogen, thereby prolonging bleeding time in mice [50]; the latter action is mediated by interaction with platelet $\alpha_{\mathrm{II}} \beta_{3}$ integrin.

\section{Phospholipase $A_{2}$}

Bothrops venoms are rich in acidic and basic $\mathrm{PLA}_{2}$ with Asp or Lys at position 49 in their active site. Many of these $\mathrm{PLA}_{2}$ cause pain, edema, inflammation and myotoxicity $[23,30]$, as well as neuromuscular blockade in vitro [91]. The content of myotoxic PLA $_{2}$ varies considerably among Bothrops species, e.g., B. asper, B. colombiensis, B. fonsecai, B. jararacussu, B. moojeni, B. neuwiedi and $B$. pradoi have an elevated content of these enzymes whereas others, such as $B$. alternatus, $B$. atrox, B. cotiara, B. erythromelas and B. jararaca, have few or no myotoxins [6,92-96]. In addition, some species, e.g., $B$. jararacussu $[14,97]$ contain a variety of $\mathrm{PLA}_{2}$ in addition to myotoxins. PLA $\mathrm{PL}_{2}$ accounted for $5.6 \%$ of $B$. alternatus venom components $(1.28 \%$ of the total EST library) (Figure 8). This PLA $_{2}$ content was similar to that of B. insularis (6.7\%) [13] and B. jararaca (6.7\%) [15], but considerably less than for $B$. atrox (14.6\%; [16]) and B. jararacussu (58\%; [14]). The $B$. alternatus $\mathrm{PLA}_{2}$ formed two major groups: those related to BOTIN PLA 2 (PA2-BOTIN or BinTX-I; SwissProt/ trEMBL accession number Q8QG87), one of two acidic Asp49 PLA $_{2}$ isoforms (BinTX-I = pI 5.05; BinTX-II = pI 4.49) characterized from the venom of $B$. insularis [98], with 41 ESTs, and those related to an acidic (pI 4.5) hypotensive Asp49 PLA 2 (Q8AXY1) from $B$. jararacussu venom [99], with 28 ESTs.

BinTX-I causes mouse hind-paw edema, as well as myonecrosis and partial neuromuscular blockade in chick biventer cervicis preparations [98]. Hence, it is probable that the corresponding $\mathrm{PLA}_{2}$ in $B$. alternatus venom exert similar effects. In contrast, the acidic hypotensive $\mathrm{PLA}_{2}$ from $B$. jararacussu is not myotoxic, cytotoxic or lethal but causes edema and hypotension, and inhibits platelet aggregation [99]. Nisenbom et al. $[51,52]$ reported the characterization of an acidic (pI 5.04-5.08) $\mathrm{PLA}_{2}$ from $B$. alternatus that accounted for most of the lethality of this venom in mice and produced cardiovascular alterations such as dyspnea, tachycardia, arrhythmia and circulatory shock, as well as tissue damage (hemorrhage, necrosis, etc.). This enzyme therefore shares properties with $B$. insularis and $B$. jararacussu $\mathrm{PLA}_{2}$.

Basic Lys49 PLA $_{2}$ S characteristic of Bothrops venoms were not detected in this venom gland library, in agreement with a proteomic analysis of this venom [90] and with EST analyses of $B$. insularis [13] and the bushmaster L. muta [18]. However, two ESTs coding for the basic $\mathrm{PLA}_{2}$ of crotoxin (the principal neurotoxin of $C . d$. terrificus; also identified in B. insularis ESTs; [13]) and one transcript for the $\mathrm{PLA}_{2} \beta$-neurotoxin ammodytoxin (from Vipera ammodytes) were detected. The general absence of basic Lys49 PLA 2 in the B. alternatus transcriptome agrees with the very low content of myotoxic 
$\mathrm{PLA}_{2}$ already reported for this venom $[93,95]$. Indeed, to date, only one basic (pI 8.63) myotoxic Lys49 PLA $_{2}$ has been isolated and characterized from this venom $[54,55]$. This $\mathrm{PLA}_{2}$, which accounts for $<1 \%$ of the venom content, causes mouse footpad edema, skeletal muscle myonecrosis, lysis of $\mathrm{C} 2 \mathrm{C} 12$ skeletal muscle myoblasts and presynaptic neuromuscular blockade in chick biventer cervicis and mouse phrenic nerve-diaphragm preparations. However, given the very low level of this $\mathrm{PLA}_{2}$ in the venom, its overall contribution to the activities of the venom is likely to be minimal.

In addition to $\mathrm{PLA}_{2}$, inhibitors of this enzyme were also detected (17 ESTs with hits only in the 3'UTR; similar to $\mathrm{PLA}_{2}$ inhibitors of Trimeresurus flavoviridis). Venom gland $\mathrm{PLA}_{2}$ inhibitors show considerable sequence identity with $\gamma$-PLI (phospholipase inhibitors) identified in snake sera, including that of B. alternatus [100].

\section{Serine proteinases}

Coagulopathy is a major complication of systemic envenoming by Bothrops species that, in conjunction with the action of venom metalloproteinases, can contribute to systemic hemorrhage $[21,28]$. Coagulation disturbances caused by Bothrops venoms are mediated by a variety of enzymes that act at various points of the coagulation cascade, including fibrinogen degradation and fibrin consumption. The clinical outcome of this combined action is incoagulable blood. Some of the serine proteinases may also have kinin-releasing activity that can contribute to local pain, vasodilation and systemic hypotension [101,102]. In the $B$. alternatus transcriptome, serine proteinases were the fourth most abundant group of toxins (Figure 8$)(1.9 \%$ and $0.45 \%$ of toxin and total transcripts, respectively), with $\sim 42 \%$ (10 ESTs) being related to BthaTL, a serine proteinase identified in this venom by Vitorino-Cardoso et al. [58] based on gene cloning and amino acid sequence analysis. This protein, which shares sequence identity $(>60 \%)$ with a variety of snake venom thrombin-like enzymes (TLE), is probably the same as the TLE balterobin previously purified and characterized by Smolka et al. [57]. Other proteins in this group were related to serine proteinase isoform 5 (7 ESTs), venom serum proteinase-like protein 2 precursor (5 ESTs) and venom serine proteinase HS112 precursor (1 EST) and TLE (1 EST). In addition, there was one transcript with a hit in a UTR for a protein similar to $\mathrm{KN}-\mathrm{BJ} 2$, a kinin-releasing, fibrinogen clotting enzyme from $B$. jararaca venom $[15,102,103]$. The range of serine proteinases identified here in ESTs agrees with the presence of coagulant (BthaTL and several TLEs homologous to ancrod, batroxobin, proteinase HS114 and pallase) and kinin-releasing enzymes identified in the proteome of this venom [90]. The abundance of serine proteinases in the $B$. alternatus transcriptome was similar to the $2 \%$ reported for B. jararacussu [14] but considerably less than in other species of this genus, e.g., ranging from $8.2 \%$ in $B$. atrox [16] to $28.6 \%$ in $B$. jararaca [15]. Differences in the relative proportion of serine proteinases present in the venoms could contribute to variations in the severity of coagulopathy among Bothrops species.

\section{C-type lectins}

Proteins with C-type lectin-like domains are widespread in the animal kingdom, including venoms. Venom Ctype lectins form two major groups: true $\mathrm{C}$-type lectins with carbohydrate binding domains and C-type lectinlike proteins with non-carbohydrate binding domains, the latter consisting mainly of factor IX/X binding proteins and proteins that interact with platelet receptors. C-type lectins are involved in venom-induced coagulation disturbances and have been identified in various Bothrops ESTs [11,13-16]. These proteins formed the fifth most abundant class of toxin transcripts in B. alternatus (18 ESTs with protein, $1.46 \%$, or $0.33 \%$ of the total cDNA library) (Figure 8) and were related to the $\alpha$ subunit of platelet glycoprotein Ib-binding protein $(8$ ESTs), the ACF $1 / 2 \beta$ chain (7 ESTs), coagulation factor IX-binding protein (2 ESTs) and bothrojaracin (1 EST). There was also a transcript for convulxin (one singlet in the 3'UTR), a C-type lectin initially identified in the venom of $C$. $d$. terrificus (also identified in B. insularis ESTs; [13]). The abundance of C-type lectins was considerably less than in $B$. atrox (4.8\%; [16]), B. insularis (14.5\%; [13]), B. jararaca (8.3\%; [15]) and B. jararacussu (5\%; [14]); if these relative proportions are reflected in the venoms, then $\mathrm{C}$-type lectins may contribute less to coagulopathy in bites by $B$. alternatus than by other Bothrops spp.

Few proteins of this class have been characterized from $B$. alternatus venom. Bothrojaracin, a $27 \mathrm{kDa}$ heterodimer $(13 \mathrm{kDa}$ and $15 \mathrm{kDa})$ initially purified from $B$. jararaca venom, is homologous to several C-type lectin family proteins and inhibits thrombin activity, e.g., platelet aggregation and fibrinogen clotting, by interacting with exosites I and II of this enzyme to form a noncovalent complex [104,105]. Castro et al. [56] characterized bothroalternin, a bothrojaracin-like protein, from $B$. alternatus venom; this protein $27 \mathrm{kDa}$ homodimer cross-reacts with antibodies to bothrojaracin, shares sequence identity (68-84\%) with the $\alpha$ and $\beta$ chains of factor IX/X binding protein and botrocetin from $B$. jararaca venom, and inhibits thrombin-induced platelet aggregation. Bothroalternin has also been detected in the proteome of $B$. alternatus [90].

Sugar-binding lectins, which are related to C-type lectins, have been detected in some Bothrops ESTs $[11,14,16]$, but were not detected here or in $B$. jararaca [15]. 


\section{Bradykinin-potentiating peptide and C-type natriuretic peptide precursors}

Bothrops venoms have long been known to contain bradykinin-potentiating peptides (BPPs) that enhance venom-induced hypotension by inhibiting angiotensinconverting enzyme, a pivotal enzyme in the formation of angiotensin II (vasoconstrictor peptide) and degradation of bradykinin (vasodilator peptide) [106]. Numerous such peptides have since been identified in Bothrops venoms ([107] and references therein), and cloning and sequence analysis studies in the late 1990s identified genes encoding BPPs in B. jararaca venom gland $[108,109]$. These same studies also reported the presence of genes encoding for C-type natriuretic peptides (CNPs) that could contribute to venom-induced hypotension. Transcriptomic studies of Bothrops venom glands have confirmed these findings and shown that genes encoding these two peptides account for 6-20\% of venom toxin ESTs $[11,13,15,16]$. A similar percentage ( 9\%) was observed here for B. alternatus (Figure 8 ), for which 110 ESTs coded for BPP/CNP precursors (specifically the CNP region) while another 156 ESTs showed similarities only in the 3'UTR. In contrast to the abundance of BPP/CNP transcripts detected in Bothrops spp. by EST analysis, proteomic analyses have shown that these peptides account for $<1 \%$ of the venom protein/ peptide content $[6,110]$, although in $B$. insularis the venom $\mathrm{BPP}$ content is $10 \%$ [11]. A similar situation applies to CNPs for which some peptidomic analyses have detected no such peptides in venom, despite the identification of transcripts in EST analyses, e.g., B. insularis [11] and L. muta ([111]; but cf. [10]) (see section on 'Inverted repeats' below for additional comment on CNP detection).

\section{Minor toxin classes \\ Cysteine-rich secretory proteins}

Snake venom cysteine-rich secretory proteins (CRISPs) are 23-26 kDa proteins with a high content of cysteine residues (16) that form eight disulfide bridges. CRISPs are widespread in snake venoms and have been detected in transcriptomic [11,13-16] and proteomic $[6,7,11,96,110,112,113]$ studies of Bothrops venoms, where they account for $0.5-2 \%$ and $0-3.6 \%$ of venom genes and toxins, respectively. In agreement with these studies, we detected five ESTs with protein $(0.4 \%$ of toxin transcripts) for CRISPs in B. alternatus venom gland. Although the role of venom CRISPs remains poorly understood, several members of this family block a variety of ion channels, including L-type $\mathrm{Ca}^{2+}$ channels, cyclic-nucleotide-gated ion channels, voltageactivated $\mathrm{K}^{+}$channels (Kv1.3), high-conductance $\mathrm{Ca}^{2+}$ activated $\mathrm{K}^{+}$channels $(\mathrm{BCa})$ and the ryanodine-sensitive intracellular $\mathrm{Ca}^{2+}$ channel. Peichoto et al. [114] have recently shown that a CRISP from the venom of the South American colubrid Philodryas patagoniensis causes myonecrosis. Since myonecrosis is an important local response to envenoming by Bothrops spp., including $B$. alternatus, it is possible that CRISPs could contribute to this activity.

\section{Dipeptidylpeptidase IV}

Dipeptidylpeptidase IV (DPP IV) (also known as CD26) has a wide distribution in snake venoms [115]. DPP IV genes have been identified in the venom glands of $B$. jararaca [15], Gloydius blomhoffii brevicaudus [116], L. muta [18] and various Australian elapids [9]. Gasparello-Clemente and Silveira [117] reported DPP IV in Bothrops venoms, with the highest activity in B. alternatus. In agreement with this, we detected a transcript coding for DDP IV protein in B. alternatus. Venom DPP IV, which has enzymatic properties similar to those of other eukaryotic DPP IV [116], may contribute to venom-induced cardiovascular alterations, possibly by degrading endogenous peptides through association with exosome-like vesicles in fresh venom [118], and possibly by interfering with glucose homeostasis and the immune and neuroendocrine systems [119]. DPP IV may also be important in processing polypeptide precursors of venom peptides, as suggested for wasp and bee venoms $[120,121]$.

\section{Growth factors}

Snake venom growth factors comprise primarily vascular endothelial growth factor (svVEGF) and nerve growth factor (NGF), both of which have been detected in Bothrops ESTs [11,13-16]. We detected five ESTs for VEGF similar to $B$. insularis VEGF $[13,122]$, one EST similar to L. muta VEGF [18] and one EST similar to $C$. d. terrificus NGF. However, the proportion of growth factor transcripts in B. alternatus was lower than in other Bothrops ESTs. Junqueira-de-Azevedo et al. [122] showed that svVEGF from $B$. insularis venom was able to increase vascular permeability and suggested that this protein could be involved in local and systemic vascular responses to envenoming.

\section{Hyaluronidase}

Hyaluronidase, which has an important role in facilitating venom diffusion from the site of inoculation through its degradation of hyaluronic acid in the extracellular matrix, is widespread in Bothrops venoms [123]. However, hyaluronidase has not generally been detected in transcriptomic and proteomic analyses of this genus, perhaps because of its low level of expression in venom glands. In agreement with this, we found only one EST similar to truncated hyaluronidase from Bitis arietans in the $B$. alternatus cDNA library.

\section{L-Amino acid oxidase}

L-Amino acid oxidase (LAO), which is widespread in Bothrops venoms [124], exerts a variety of biological 
activities, including interference with platelet aggregation, cytotoxicity and microbicidal activity $[87,88]$. These deleterious effects are mediated largely via the production of $\mathrm{H}_{2} \mathrm{O}_{2}$ during the oxidation of $\alpha$-keto amino acids. LAO accounts for $0.5-2.6 \%$ of toxin transcripts in Bothrops venom gland transcriptomes [13-16] and has been purified and characterized from these venoms [88]. In the case of $B$. alternatus, we detected seven ESTs for this toxin in the nucleotide region: four of these were related to LAO from B. jararaca and three were ESTs in the 3'UTR related to Ophiophagus hannah LAO. In contrast to this low transcript abundance, LAO accounted for $6.9 \%$ of the venom proteins identified in a proteomic analysis of B. alternatus venom [90]. LAO purified from $B$. alternatus venom is an acidic ( $\mathrm{pI}$ 5.37), homodimeric (123 kDa) glycoprotein that induces platelet aggregation, causes edema, is bactericidal and slightly hemorrhagic [59]; this enzyme may contribute to the cytotoxicity of $B$. alternatus venom in cultured Madin-Darby canine kidney (MDCK) cells [125].

\section{Three-finger toxins (3-FTx)}

Three-finger toxins (3-FTx) consist predominantly of elapid neurotoxins, including $\alpha$-neurotoxins, cardiotoxins and fasciculins, and a variety of less well-characterized venom proteins $[126,127]$. Originally thought to be restricted to elapids, 3-FTx have since been identified in crotalid [18,128] and colubrid $[127,129,130]$ venom glands. 3-FTx exert a variety of biological activities that include blockade of acetylcholine (nicotinic and muscarinic) receptors, $\beta$-adrenergic receptors, Ltype calcium channels and integrins, inhibition of acetylcholinesterase, and cardiotoxicity mediated by interation with phospholipids.

We identified 30 ESTs for 3-FTx in the B. alternatus venom gland library ( $0.56 \%$ of total ESTs; $2.4 \%$ of toxin ESTs) that shared $90 \%$ similarity with the intron II region of the gene for 3FTx-3 from Sistrurus catenatus edwardsi [128], but no hits with colubrid, elapid or $L$. muta [18] 3-FTx. Pahari et al. [128] also noted that the 3-FTx nucleotide and protein sequences of $S . c$. edwardsi bore no relationship to those of L. muta, a finding confirmed by phylogenetic analysis that placed the L. muta toxins distant from those of S. c. edwardsi. Complete sequencing of the $B$. alternatus genes would be helpful in determining the precise relationship between these 3-FTx and those of S. c. edwardsi.

This is the first identification of 3-FTx genes in Bothrops and, together with other studies, suggests that this class of toxins may occur in a variety of New World pitvipers, i.e., Bothrops [this study], Sistrurus [128] and Lachesis [18] (based on transcriptomic analyses) and Atropoides mexicanus (nummifer) (but not in Atropoides picadoi) (based on proteomic analysis) [131]. However, transcriptomic analyses have not detected these toxins in other New World pitvipers, e.g., Agkistrodon piscivorus leucostoma [132] and C. d. collilineatus [17], or in Old World pitvipers (Agkistrodon (Deinagkistrodon) acutus $[133,134]$ ) and vipers (Bitis gabonica [61] and Echis species $[12,135])$. In addition to this inter-generic variation, there is also intra-generic variation in the occurrence of 3-FTx. Thus, whereas 3-FTx have been detected in a transcriptomic analysis of S. c. edwardsi [128], these toxins have not been detected in a proteomic analysis of venoms from several members of this genus [136]. Likewise, A. mexicanus (nummifer) venom, but not that of A. picadoi, contains 3-FTx [128]. Such variation may reflect the low abundance of transcripts and proteins (making their detection difficult) and/or the non-uniform recruitment of these toxins into the venom proteome [128]. This could explain why transcriptomic [11,13-16] and proteomic $[6,7,11,96,110,112,113,137]$ analyses have generally not detected these genes and proteins in Bothrops species.

The physiological relevance of 3-FTx to envenoming by Bothrops species is unclear, particularly in view of the low transcript abundance indicated by our results. However, Bothrops venoms cause neuromuscular blockade in avian and mammalian nerve-muscle preparations in vitro [138]. Although most of this activity has been attributed to the action of basic myotoxic PLA 2 [91], 3FTx could also contribute to this response through their ability to interfere with neuromuscular transmission.

\section{Ohanin}

Envenoming by Bothrops species results in local pain at the bite site $[21,28]$. Venom components implicated in this phenomenon include PLA 2 , metalloproteinases and serine proteinases that act via the release of endogenous mediators such as arachidonic acid metabolites (leucotrienes and prostaglandins), bradykinin, proinflammatory cytokines and neuronal nitric oxide $[23,24,26]$. In contrast, little is known of the involvement of other Bothrops venom proteins in this pain. The identification here of 24 ESTs with hits in the 3'UTR of the precursor for ohanin, an $\sim 12 \mathrm{kDa}$ hypolocomotion and hyperalgesic protein initially identified in the venom of the king cobra, O. hannah, and part of the vespryn family of proteins $[139,140]$, indicates that other venom proteins, in addition to those indicated above, may be involved in Bothrops venom-induced pain. Since its initial identification, ohanin (vespryn) has been found in Australian elapids [9,141] and pitvipers such as A. acutus [133], C. d. collilineatus [17] and L. muta [18]. Our finding is the first report for ohanin in Bothrops venom glands. Together, these reports indicate that ohanins (and vespryns in general) are likely to be widespread in snake venoms where they may contribute to venom-induced hyperalgesia. 


\section{Taicatoxin-like protein}

We detected two ESTs coding for a protein related to the serine proteinase inhibitor component of taicatoxin (TCX), a multimeric protein composed of an $\alpha$-neurotoxin-like peptide $(8 \mathrm{kDa})$, a neurotoxin $\mathrm{PLA}_{2}(16 \mathrm{kDa})$ and a serine proteinase inhibitor $(7 \mathrm{kDa})$ (1:1:4 stoichiometry) initially isolated from the venom of the Australian taipan (Oxyuranus scutellatus scutellatus) [142,143]. TCX blocks high threshold, voltage-dependent calcium channel currents in cardiac membranes and cultured ventricular myocytes, although there may also be a role for the $\mathrm{PLA}_{2}$ activity in the action of this toxin $[143,144]$. The role of putative TCX-like proteins in $B$. alternatus is unclear but could contribute to the cardiovascular actions of this venom.

\section{Other toxins}

In addition to the foregoing toxins, we identified a low number of hits for several other toxins with BLAST results only in the nucleotide database. These hits included toxins related to cardiotoxins (12 reads), a muscarinic-like toxin (three reads) related to that of Bungarus multicinctus, precursors similar to post-synaptic $\alpha$-neurotoxin NTX-2 from Naja sputatrix (one contig) and neurotoxin 6 , and a molecule related to cobravenom factor (one read).

\section{Putative toxins}

Snake venoms contain a variety of nucleotidases (phosphodiesterases, 5'-nucleotidase, acid and alkaline phosphatases and ADP/ATPases) and nucleases (deoxyribonuclease - DNase and ribonuclease - RNase) that have a potentially important role in envenoming, particularly in affecting platelet aggregation and cardiovascular responses (hypotension, vascular permeability) $[119,145]$. In agreement with this, we obtained transcripts coding for a variety of genes related to some of these proteins, including an acidic DNase similar to a mouse DNAse II $\alpha$ (lysosomal DNase) precursor (3 ESTs), ecto-5'-nucleotidases (one EST coding for the enzyme in zebrafish, Danio rerio, and another transcript coding for the same enzyme in horse, Equus caballus), ectonucleotide pyrophosphatase/phosphodiesterase 3 (two ESTs, one each for monkey, Macaca mulatta, and mouse, Mus musculus) and an adenosine deaminase related to Xenopus laevis enzyme (one transcript). Although several of these genes have been detected in other transcriptomic analyses [13,18,61,133,135], it is currently unclear whether the corresponding proteins are secreted into the venom or simply part of normal intracellular metabolism in the venom gland. We have purified phosphodiesterase [60], 5'-nucleotidase and an acidic DNase (DNase II) (unpublished findings) from $B$. alternatus venom, but since the structure of these proteins is unknown it is unclear to what extent they share similarity with the proteins coded by the genes identified in the venom gland ESTs. Ogawa et al. [146] have recently shown that G. blomhoffi ecto-5'-nucleotidase is structurally similar to this enzyme from various other vertebrates.

Other genes identified that could potentially be involved in envenoming included a cytokine-like protein (one EST similar to horse cytokine) (also identified in other snake venom ESTs [61,133]) and tumor necrosis factor (two ESTs similar to chicken, Gallus gallus, protein), both of which could contribute to the venominduced local inflammatory response.

\section{Selected features of $B$. alternatus venom gland ESTs Single nucleotide polymorphisms and simple repeats (microsatellites)}

Polymorphisms in the nucleic acid sequences of snake venom proteins, particularly $\mathrm{PLA}_{2}$, have been identified in several species $[147,148]$. These genetic modifications arise from rapid gene duplication followed by single nucleotide polymorphisms (SNPs), with an increase in non-synonymous nucleotide substitutions that alter the DNA sequence encoding the protein. Ohno et al. [147] suggested that such alterations result in the rapid appearance of novel toxins with different biological activities. Our analysis revealed 132 putative SNPs in the $B$. alternatus transcriptome, of which 31 (16 nonsynonymous and 15 synonymous substitutions) were located in ORFs, as determined based on alignment against the UniProt database. In addition, we identified 32 insertion-deletion polymorphisms (indels) (Table 1; Additional file 1). Although not extensively studied, detailed analysis of venom protein SNPs could be useful for population genetic studies and for assessing the importance of rapid sequence changes in generating the observed diversity of genes involved in venom production [148].

The screening of unisequences with the tandem repeats finder tool resulted in the identification of 321 sequences with possible microsatellite regions; when annotated sequences with transposable elements (TEs) were excluded, 244 sequences with microsatellite regions were identified (data not shown). These sequences could be potentially useful for the development of molecular markers for characterization of the genetic variability and population structure of $B$. alternatus throughout its geographic distribution.

\section{Transposable elements}

Eukaryotic genomes contain a large number of repeated sequences, a high proportion of which may consist of transposable elements (TEs). In snakes, TEs have been previously identified in $\mathrm{PLA}_{2}$ genes from the venom gland of Vipera ammodytes $[149,150]$. These TEs are ruminant retroposons corresponding to 5'-truncated 
Bov-B long interspersed repeated DNA (LINE) and were identified in ammodytin $\mathrm{L}$ (a natural mutant of a group II $\mathrm{PLA}_{2}$ ) and ammodytoxin C (similar structure to other mammalian group II PLA ${ }_{2}$ ) genes. Alignments meeting our criteria (see Methods) allowed the identification of repeated elements in 492 unisequences, which corresponded to $9 \%$ of the B. alternatus ESTs (Additional file 2); (retro)transposons have also been identified in $B$. insularis [13] and L. muta [18]. Several TE families were identified among the $B$. alternatus transcripts, the most abundant being BovB, which was identified in 120 unisequences (Table 2). The expression of these TE families indicated that the genome harbored a large number of potentially active elements that gave rise to a variety of ESTs.

Further examination of the 492 unisequences harboring TEs revealed that 193 of them were fused to a sequence not included in the repeats database. To determine the identity of these sequences, we masked the TEs and BLASTed the masked unisequences against the GeneBank nr database. This approach revealed that in 80 unisequences, the TE was fused to a protein-coding gene (Additional file 3). Most transposition events involving protein-coding regions are deleterious to host genomes because they disrupt mRNA translation, localization and stability. However, since TEs associated with $\mathrm{PLA}_{2}$ genes have been found to be transcribed $[136,137]$, we hypothesize that the TEs in B. alternatus may act as a source of genetic novelty by playing an important role in the origin and diversity of toxin genes. Inverted repeats

The alignment of $B$. alternatus unisequences to corresponding reference genes indicated that some of the genes contained long inverted repeats (IR) in which a segment of the sequence was inverted from its original orientation in the reference gene (Additional file 4). An interesting example of such inversions involved genes for BPPs/CNPs, for which 16 unisequences with inverted repeats were observed (data not shown). Figure 10 shows the case in which an IR occurred in a portion of mRNA coding for part of a CNP. As mentioned above in the discussion of CNP genes, although EST studies have indicated the presence of genes for these peptides in Bothrops and Lachesis species, proteomic studies have not always been successful in isolating and identifying these peptides [11,111]. The reason for this discrepancy between EST and proteomic findings has not been adequately addressed but one explanation could be related to the occurrence of IR in these genes that may interfere with adequate gene transcription and/ or translation in vivo, thereby preventing toxin production.

The origin of such IR transcripts is unclear. Theoretically, they could be artifacts generated by end-to-end joining of non-contiguous cDNA sequences and template switching by reverse transcriptase during cDNA synthesis; template switching can artificially delete portions of cDNAs and be wrongly interpreted as alternative transcripts. During first strand cDNA synthesis, poly $(\mathrm{A})+$ RNAs are primed by an oligo(dT) and when the reverse transcriptase reaches the 5'-end of the junction site in the mRNA, the nascent cDNA switches the template to the IR in the antisense mRNA that will now be used as a new template. However, since the homologous recombination between two RNA templates promoted by reverse transcriptase requires RNase $\mathrm{H}$ activity, and since the PowerScript ${ }^{\mathrm{Tm}}$ Reverse Transcriptase used here for cDNA synthesis lacked RNase $\mathrm{H}$ activity, it seems unlikely that homology-dependent template switching could have generated these hybrid cDNAs artificially.

Further reasons that the IR observed here are unlikely to be artifacts include the following: 1) end-to-end joining during library construction would randomly ligate molecules and one would expect not only intra-molecular hybrids but also ligation of independently transcribed mRNAs, 2) in the case of an artifact, the transcript of highest abundance would be expected to be frequently ligated to other transcripts to form inter-molecular hybrids, but this was not observed in our library, and 3) the finding that the same ESTs containing inversions were present in multiple sequence reads from the same library and in independent libraries. Together, these observations suggest that this phenomenon was not an artifact.

\section{Comparison of the B. alternatus transcriptome with other Bothrops species}

Following the initial report of gene expression analysis in the venom gland of $B$. insularis ([13], recently updated by Valente et al. [11]), similar studies were reported for other Bothrops species, including B. atrox [16], B. jararaca [15] and B. jararacussu [14]. The availability of data for several Bothrops species provides an opportunity to compare related species and draw some general conclusions regarding venom composition in this genus. Few such transcriptomic comparisons are available for other genera [135].

To date, our study represents the largest EST database for Bothrops; the 5,350 ESTs reported here considerably exceed those reported for B. atrox (610) [16], B. insularis (initially 610, but updated to 2042) [11,13], B. jararaca (2318) [15] and B. jararacussu (549) [14]. We chose to generate a larger database than those previously reported for Bothrops species in an attempt to identify novel genes in addition to the main toxin groups already known for this genus. Indeed, this larger database allowed the detection of genes for toxins such 
Table 1 Single nucleotide polymorphism (SNP) positions in the B. alternatus venom gland cDNA library

\begin{tabular}{|c|c|c|c|}
\hline Contig & Length (bp) & SNPs & First hit \\
\hline Contig531 & 1006 & 9 & Jararhagin [Bothrops jararaca] \\
\hline Contig473 & 749 & 6 & Zinc metalloproteinase-disintegrin ACLD precursor [Gloydius brevicaudus] \\
\hline Contig425 & 844 & 6 & Zinc metalloproteinase/disintegrin precursor [Bothrops insularis] \\
\hline Contig500 & 715 & 5 & Protein disulfide isomerase 3 precursor [Gallus gallus] \\
\hline Contig322 & 700 & 4 & ATP synthase F0 subunit 6 [Agkistrodon piscivorus] \\
\hline Contig662 & 1213 & 3 & Hypothetical 18K protein - goldfish mitochondrion \\
\hline Contig310 & 568 & 2 & Predicted: hypothetical protein [Gallus gallus] \\
\hline Contig 54 & 758 & 2 & Zinc metalloprotease-disintegrin halysase precursor [Gloydius halys] \\
\hline Contig538 & 784 & 2 & Ribosomal protein S2 [Homo sapiens] \\
\hline Contig117 & 281 & 1 & Similar to ribosomal protein L34 [Monodelphis domestica] \\
\hline Contig285 & 594 & 1 & Phospholipase $\mathrm{A}_{2}$ BITP01A precursor [Bothrops insularis] \\
\hline Contig278 & 762 & 1 & Unnamed protein product [Homo sapiens] \\
\hline Contig181 & 763 & 1 & Predicted: similar to calmodulin [Mus musculus] \\
\hline Contig384 & 789 & 1 & Piscivorin precursor [Agkistrodon piscivorus] \\
\hline Contig 26 & 1001 & 1 & Zinc metalloproteinase/disintegrin precursor [Bothrops jararaca] \\
\hline Contig349 & 1051 & 1 & Calreticulin [Gallus gallus] \\
\hline Contig149 & 1313 & 1 & Predicted: similar to PLC $\alpha$, partial [Ornithorhynchus anatinus] \\
\hline Contig335 & 1448 & 1 & Cytochrome oxidase subunit 1 [Campephilus guatemalensis] \\
\hline Contig840 & 1891 & 1 & Zinc metalloproteinase-disintegrin jararhagin precursor [Bothrops jararaca] \\
\hline Contig255 & 745 & 1 & Predicted: similar to U2 (RNU2) small nuclear RNA [Pan troglodytes] \\
\hline
\end{tabular}

The polymorphisms were detected using the program TrueSNP, with the highest number being detected in genes related to jararhagin from $B$. jararaca.

as ohanin and 3-FTx, previously identified in other snake genera but not in Bothrops, in addition to nonvenom proteins such as DUSP6 and thioredoxin.

The generation of a large database for $B$. alternatus did not significantly alter the profile of the most common toxin groups (metalloproteinases, BPPs/CNPs, $\mathrm{PLA}_{2}$, serine proteinases, C-type lectins, growth factors, etc.) when compared with other Bothrops species. This finding suggests that a large database is not essential for identification of the major toxin groups but can be useful for increasing the chances of detecting toxins with very low transcript abundance. This conclusion agrees with data for $B$. insularis in which increasing the EST database from 610 [13] to 2042 [11] ESTs did not markedly alter the relative proportions of metalloproteinases ( $41.7 \%$ vs. $43.2 \%$, for 610 vs. 2042 ESTs), BPPs/CNPs ( $19.7 \%$ vs. $15.8 \%)$, C-type lectins (14.6\% vs. $14.2 \%)$, serine proteinases $(9.6 \%$ vs. $11.2 \%), \mathrm{PLA}_{2}(6.7 \%$ vs. $5.4 \%)$,

Table 2 Occurrence of transposable elements (TEs) in the B. alternatus venom gland cDNA library

\begin{tabular}{llll}
\hline Family & Name & Genus in which originally described & B. alternatus unisequences \\
\hline RTE & BovB & Vipera (snake) & 120 \\
CR1 & CR1_HS & Homo (human) & 19 \\
L2 & LINE2_CH1 & Crotalus (snake) & 15 \\
hAT & HAT3_MD & Monodelphis (rat) & 13 \\
L2 & LINE2_NT1 & Natrix (snake) & 8 \\
hAT-Charlie & SPIN_Ml & Myotis (bat) & 6 \\
hAT-Charlie & URR1_Xt & Xenopus (frog) & 4 \\
L2 & LINE2_WA1 & Walterinnesia (snake) & 3 \\
hAT-Charlie & SPIN_Og & Otolemur (primate) & 3 \\
TCMar-Tc1 & TC1-3_Xt & Xenopus (frog) & 3 \\
hAT-Charlie & nhAT4b_ML & Myotis (bat) & 2 \\
hAT-Charlie & SPIN_NA_6_Et & Echinops (plant) & 2 \\
Sauria & AFESINE & Azemiops (snake) & 1 \\
R4 & Rex6 & Takifugu (fish) & 1 \\
TcMar-Tc1 & TC1-2_FR & Takifugu (fish) & 1 \\
TcMar-Tc1 & TZF28B & Danio (fish) & 1 \\
\hline
\end{tabular}

The most frequently encountered TE was BovB, also identified in Vipera. 
svVEGF ( $4.3 \%$ vs. $4.7 \%)$, LAO (2.6\% vs. $3.5 \%)$, CRISPs $(0.6 \%$ vs. $1.5 \%)$ and NGF (0.3\% vs. $0.4 \%)$. In the present study, $78 \%$ of the hits corresponded to toxin transcripts, which compares favorably with values for other Bothrops species $(54 \%-78 \%)[11,13-16]$ and indicates that the relative proportion of toxin transcripts is not directly related to the size of the cDNA library.

Conversely, the generation of a large database resulted in a considerably greater number of no-hits: $70 \%$ in this study compared to $13 \%-25 \%$ for other Bothrops studies
[11,13-16] and $7 \%-54 \%$ for other snake genera [12,18-20,61,128,132-135]. These no-hits reflect the limited amount of information available for Bothrops species and other snakes in venom gland EST databases, and represent a potentially rich source for the identification of novel toxins.

Figure 11 compares the relative abundance of the major toxin classes observed in Bothrops species based on EST analyses. In all cases, there was a predominance of metalloproteinases, BPPs, $\mathrm{PLA}_{2}$, serine proteinases

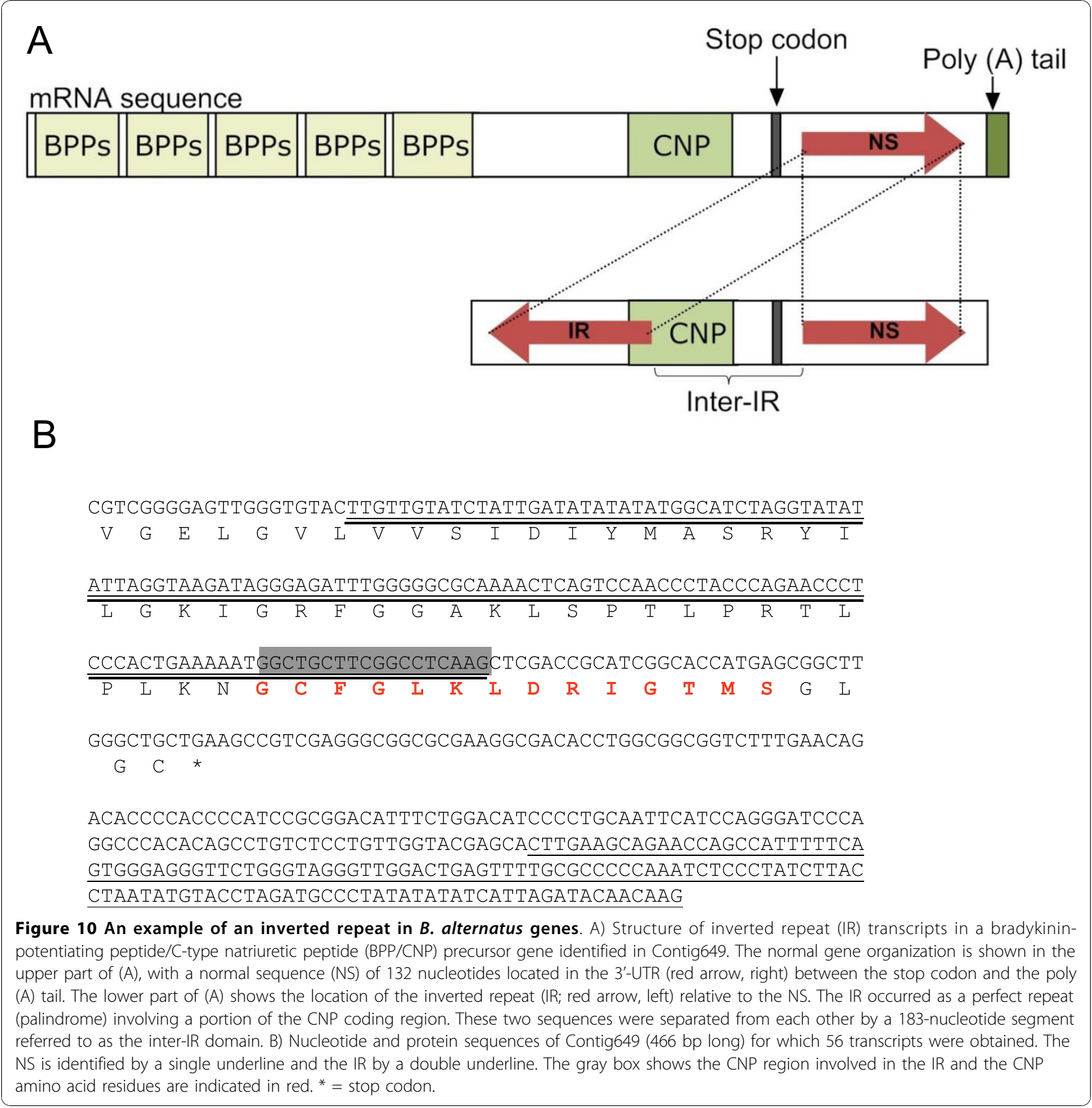




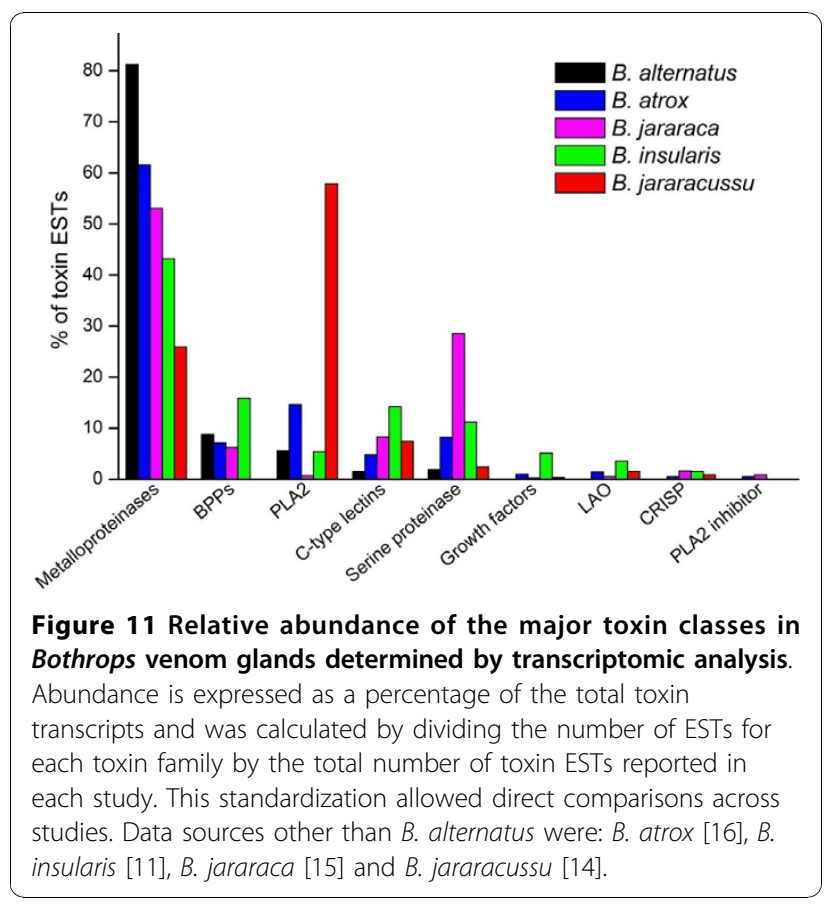

and C-type lectins, with less abundant groups being LAO, CRISPs and growth factors (principally svVEGF and NGF). There was considerable inter-specific variation in the content of the major toxin. Thus, B. alternatus had the highest proportion of metalloproteinase transcripts among the five species, being more than three-fold more abundant than in B. jararacussu. PLA $_{2}$ abundance was similar to $B$. insularis, greater than $B$. jararaca but less than $B$. atrox and B. jararacussu; the latter species was the only one in which $\mathrm{PLA}_{2}$ transcripts were more abundant than metalloproteinases (at least two-fold greater). The proportion of BPP/CNP transcripts in $B$. alternatus was similar to $B$. atrox and $B$. jararaca but about half that of $B$. insularis, while serine proteinases and $C$-type lectins were generally less abundant than in other Bothrops species. As indicated above, a lower content of serine proteinases and C-type lectins in the venom could account for the less severe coagulopathy observed clinically for envenoming by B. alternatus compared to other Bothrops species [36]. Despite the inter-specific variation in the relative proportion of toxin classes, these findings confirm that most Bothrops venom components can be classified into a few major groups. This conclusion agrees with proteomic analyses of Bothrops venoms that have also identified these groups as the major toxin families $[6,7,11,90,96,97,110,112,113,137]$ (Figure 12). In addition to inter-specific variation, these proteomic studies have also reported individual, age-dependent and geographic variation in the toxin content of these major classes $[110,112,137]$.

For five Bothrops species (B. alternatus, B. atrox, B. insularis, B. jararaca and B. jararacussu) there are

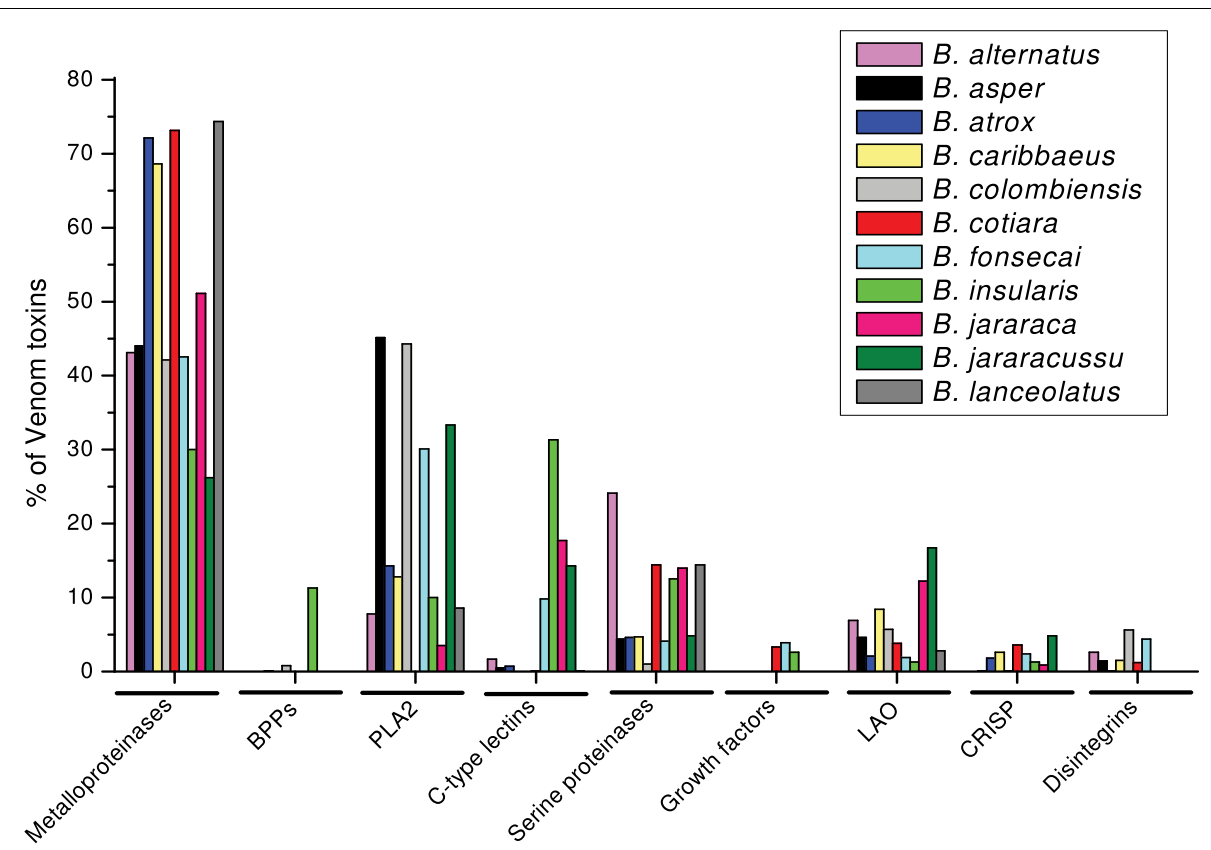

Figure 12 Relative abundance of the major toxin classes in Bothrops venoms determined by proteomic analysis. Abundance is expressed as a percentage of the total number of toxins identified in each analysis. Data sources were: B. alternatus [90], B. asper (Pacific population) [112,113], B. atrox (Brazilian population) [110], B. caribbaeus [7], B. colombiensis [6], B. cotiara [96], B. fonsecai [96], B. insularis [11], B. jararaca [103], B. jararacussu [97] and B. lanceolatus [7]. 
transcriptomic and proteomic analyses that allow comparison of the toxin frequencies in the different classes. For metalloproteinases and PLA $\mathrm{P}_{2}$, there is reasonably good agreement between the proportion of transcripts and the corresponding levels of these proteins detected in the venoms, whereas for other classes, e.g., BPPs, C-type lectins and serine proteinases, there are often marked discrepancies between the transcriptomic and proteomic data (cf. Figures 11 and 12). In the case of $B$. alternatus, there was good agreement between the proportion of ESTs (this study) and venom content [90] of $\mathrm{PLA}_{2}$ (5.5\% vs $7.8 \%$, respectively) and C-type lectins (1.4\% vs. $1.7 \%)$, but considerable divergence between these two data sets in the case of metalloproteinases $(81.4 \%$ vs. $43.1 \%)$, serine proteinases $(1.9 \%$ vs. $24.1 \%)$ and LAO $(0.6 \%$ vs. $6.9 \%)$ [this study and ref. [90]]. Divergent transcriptomic and proteomic results have also been observed for certain toxin groups in other snake genera, e.g., Echis species [12] and L. muta [10]. The causes and implications of such discrepancies have been discussed elsewhere [3] and indicate the need for caution in interpreting transcriptomic data as being representative of the final venom composition.

Finally, it should be noted that the principal toxin classes identified by transcriptomic and proteomic analyses are those that have been shown to contribute to the major local and systemic effects produced by these venoms, i.e., potent hemorrhagic activity (mediated by metalloproteinases), extensive myonecrosis (myotoxic PLA $\mathrm{P}_{2}$ ), inflammatory responses (metalloand serine proteinases, $\mathrm{PLA}_{2}$ ), coagulopathy (C-type lectins, serine proteinases, disintegrins) and cardiovascular actions (metalloproteinases, $\mathrm{PLA}_{2}$, serine proteinases such as kallikrein-like enzymes, and peptides such as BPPs) seen experimentally and clinically [21,22,26-30].

\section{Conclusions}

An EST database containing 5,350 ESTs was produced for the venom gland of $B$. alternatus, the largest to date for the genus Bothrops. The venom gland expressed the major toxin groups (metalloproteinases, $\mathrm{PLA}_{2}$, serine proteases, C-type lectins and BPP/CNPs) identified in transcriptomic and proteomic analyses of other Bothrops species. In addition, genes for toxins (ohanin, 3-FTx and taicatoxin-like protein) and non-venom components (Dusp6 and thioredoxin) not previously detected in Bothrops venoms were also observed in this gland. The results described here expand our understanding of the composition of $B$. alternatus venom and help to explain the major symptoms associated with envenoming by this species.

\section{Additional material}

Additional file 1: Table showing the positions and descriptions of SNPs identified in B. alternatus ESTs using the program QualitySNP [72]

Additional file 2: Table of transposable elements identified in $B$. alternatus ESTs.

Additional file 3: Table of transposable elements fused with proteins in B. alternatus ESTs.

Additional file 4: Table of inverted repeats (IR) identified in $B$. alternatus ESTs.

\section{Abbreviations}

BPP: bradykinin-potentiating peptide; CNP: C-type natriuretic peptide; CRISP. cysteine-rich secretory protein; DPP IV: dipeptidylpeptidase IV; EST: expressed sequence tags; 3-FTx: three-finger toxin; IR: inverted repeat; NGF: nerve growth factor; nr: non-redundant; nt: nucleotide database; ORF: open reading frame; SNP: single nucleotide polymorphism; SVMP: snake venom metalloproteinase; svVEGF: snake venom vascular endothelial growth factor; TE: transposable element; TLE: thrombin-like enzyme; UTR: untranscribed region.

\section{Acknowledgements}

The authors thank Daniela Stancato for technical assistance and Aline da Costa Lima for help in preparing the figures for the manuscript. K.C.C. is supported by a doctoral studentship from Fundação de Amparo à Pesquisa do Estado de São Paulo (FAPESP). S.H. is supported by a research fellowship from Conselho Nacional de Desenvolvimento Científico e Tecnológico (CNPq). This work was supported by CNPq.

\section{Author details}

'Departamento de Farmacologia, Faculdade de Ciências Médicas, Universidade Estadual de Campinas (UNICAMP), CP 6111, 13083-970, Campinas, SP, Brazil. 'Centro de Biologia Molecular e Genética (CBMEG), Universidade Estadual de Campinas (UNICAMP), 13083-970, Campinas, SP, Brazil. '3 Departamento de Genética, Evolução e Bioagentes, Instituto de Biologia, Universidade Estadual de Campinas (UNICAMP), CP 6109, 13083970, Campinas, SP, Brazil.

\section{Authors' contributions}

KCC was responsible for most of the experimental work, sequence annotation, data analysis, and wrote the paper under the supervision of $\mathrm{SH}$. MJDS did part of the experimental work, provided day-to-day supervision of the experimental work and analyzed the results. GGLC performed the bioinformatics analyses, annotated the sequences and helped draft the manuscript. TTT helped with the bioinformatics analyses and manuscript preparation. LEVDB contributed to the sequence annotation. RV helped with the bioinformatics analyses. MM was involved in delineating the experimental design in the initial stages of the work and contributed to discussions of early experiments. SH conceived and wrote the project (together with KCC), supervised the project, helped in analyzing the results, and wrote the paper with KCC. All authors read and commented on the manuscript before submission.

\section{Competing interests}

The authors declare that they have no competing interests.

Received: 2 March 2010 Accepted: 26 October 2010

Published: 26 October 2010

\section{References}

1. Ménez A, Stöcklin R, Mebs D: 'Venomics' or: The venomous systems genome project. Toxicon 2006, 47:255-259.

2. Calvete JJ, Juárez P, Sanz L: Snake venomics. Strategy and applications. $J$ Mass Spectrom 2007, 42:1405-1414. 
3. Fox JW, Serrano SMT: Exploring snake venom proteomes: multifaceted analyses for complex toxin mixtures. Proteomics 2008, 8:909-920.

4. Georgieva D, Arni RK, Betzel C: Proteome analysis of snake venom toxins: pharmacological insights. Expert Rev Proteomics 2008, 5:787-797.

5. Escoubas P, King GF: Venomics as a drug discovery platform. Expert Rev Proteomics 2009, 6:221-224.

6. Calvete JJ, Borges A, Segura A, Flores-Díaz M, Alape-Girón A, Gutiérrez JM, Diez N, De Sousa L, Kiriakos D, Sánchez E, Faks JG, Escolano J, Sanz L: Snake venomics and antivenomics of Bothrops colombiensis, a medically important pitviper of the Bothrops atrox-asper complex endemic to Venezuela: contributing to its taxonomy and snakebite management. $J$ Proteomics 2009, 72:227-240.

7. Gutiérrez JM, Sanz L, Escolano J, Fernández J, Lomonte B, Angulo Y, Rucavado A, Warrell DA, Calvete JJ: Snake venomics of the Lesser Antillean pit vipers Bothrops caribbaeus and Bothrops lanceolatus: correlation with toxicological activities and immunoreactivity of a heterologous antivenom. J Proteome Res 2008, 7:4396-4408.

8. Gutiérrez JM, Lomonte B, León G, Alape-Girón A, Flores-Díaz M, Sanz L, Angulo $Y$, Calvete JJ: Snake venomics and antivenomics: proteomic tools in the design and control of antivenoms for the treatment of snakebite envenoming. J Proteomics 2009, 72:165-182

9. St. Pierre L, Birrell GW, Earl ST, Wallis TP, Gorman JJ, de Jersey J, Masci PP, Lavin MF: Diversity of toxic components from the venom of the evolutionarily distinct black whip snake, Demansia vestigiata. J Proteome Res 2007, 6:3093-3107.

10. Sanz L, Escolano J, Ferretti M, Biscoglio MJ, Rivera E, Crescenti EJ, Angulo Y, Lomonte B, Gutiérrez JM, Calvete JJ: Snake venomics of the South and Central American bushmasters. Comparison of the toxin composition of Lachesis muta gathered from proteomic versus transcriptomic analysis. J Proteomics 2008, 71:46-60.

11. Valente $R H$, Guimarães $P R$, Junqueira $M$, Neves-Ferreira $A G$, Soares $M R$, Chapeaurouge A, Trugilho MR, León IR, Rocha SL, Oliveira-Carvalho AL, Wermelinger LS, Dutra DL, Leão LI, Junqueira-de-Azevedo IL, Ho PL, Zingali RB, Perales J, Domont GB: Bothrops insularis venomics: a proteomic analysis supported by transcriptomic-generated sequence data. $J$ Proteomics 2009, 72:241-255.

12. Wagstaff SC, Sanz L, Juárez P, Harrison RA, Calvete JJ: Combined snake venomics and venom gland transcriptomic analysis of the ocellated carpet viper, Echis ocellatus. J Proteomics 2009, 71:609-623.

13. Junqueira-de-Azevedo ILM, Ho PL: A survey of gene expression and diversity in the venom glands of the pit viper snake Bothrops insularis through the generation of expressed sequence tags (ESTs). Gene 2002, 299:279-291.

14. Kashima S, Roberto PG, Soares AM, Astolfi-Filho S, Pereira JO, Giuliati S, Faria M Jr, Xavier MAS, Fontes MRM, Giglio JR, França SC: Analysis of Bothrops jararacussu venomous gland transcriptome focusing on structural and functional aspects: 1 - gene expression profile of highly expressed phopholipases $A_{2}$. Biochimie 2004, 86:211-239.

15. Cidade DAP, Simão TA, Dávila AMR, Wagner $G$, Junqueira-de-Azevedo ILM Ho PL, Bon C, Zingali RB, Albano RM: Bothrops jararaca venom gland transcriptome: analysis of the gene expression pattern. Toxicon 2006, 48:437-461.

16. Neiva M, Arraes FB, de Souza JV, Rádis-Baptista G, Prieto da Silva AR, Walter ME, de Macedo Brigido M, Yamane T, López-Lozano JL, AstolfiFilho S: Transcriptome analysis of the Amazonian viper Bothrops atrox venom gland using expressed sequence tags (ESTs). Toxicon 2009, 53:427-436.

17. Boldrini-França J, Rodrigues RS, Fonseca FP, Menaldo DL, Ferreira FB, Henrique-Silva F, Soares AM, Hamaguchi A, Rodrigues VM, Otaviano AR, Homsi-Brandeburgo Ml: Crotalus durissus collilineatus venom gland transcriptome: analysis of gene expression profile. Biochimie 2009, 91:586-595.

18. Junqueira-de-Azevedo ILM, Ching ATC, Carvalho E, Faria F, Nishiyama MY Jr, Ho PL, Diniz MRV: Lachesis muta (Viperidae) cDNAs reveal diverging pit viper molecules and scaffolds typical of cobra (Elapidae) venoms: implications for snake toxin repertoire evolution. Genetics 2006, 172:877-889.

19. Leão LI, Ho PL, Junqueira-de-Azevedo ILM: Transcriptomic basis for an antiserum against Micrurus corallinus (coral snake) venom. BMC Genomics 2009, 10:112.
20. Ching ATC, Rocha MMT, Paes Leme AF, Pimenta DC, Furtado MFD, Serrano SMT, Ho PL, Junqueira-de-Azevedo ILM: Some aspects of the venom proteome of the Colubirdae snake Philodryas olfersii revealed from a Duvernoy's (venom) gland transcriptome. FEBS Lett 2006, 580:4417-4422.

21. Warrell DA: Snakebites in Central and South America: epidemiology, clinical features and clinical management. In Venomous Reptiles of the Western Hemisphere. Volume 2. Edited by: Campbell JA, Lamar WW. Ithaca: Comstock Publishing Associates/Cornell University Press; 2004:709-761.

22. Gutiérrez JM, Lomonte B: Efectos locales en el envenenamiento ofídico en América Latina. In Animais Peçonhentos no Brasil: Biologia, Clínica e Terapêutica dos Acidentes. Edited by: Cardoso JLC, França FOS, Wen FH, Málaque CMS, Haddad V Jr. São Paulo: Sarvier/FAPESP; 2003:310-323.

23. Teixeira CF, Landucci EC, Antunes E, Chacur M, Cury Y: Inflammatory effects of snake venom myotoxic phospholipase $A_{2}$. Toxicon 2003, 42:947-962.

24. Teixeira C, Cury Y, Moreira V, Picolo G, Chaves F: Inflammation induced by Bothrops asper venom. Toxicon 2009, 54:988-997.

25. Pinho FM, Yu L, Burdmann EA: Snakebite-induced acute kidney injury in Latin America. Semin Nephrol 2008, 28:354-362.

26. Gutiérrez JM, Rucavado A, Chaves F, Díaz C, Escalante T: Experimental pathology of local tissue damage induced by Bothrops asper snake venom. Toxicon 2009, 54:958-975.

27. Gutiérrez JM, Escalante T, Rucavado A: Experimental pathophysiology of systemic alterations induced by Bothrops asper snake venom. Toxicon 2009, 54:976-987.

28. França FOS, Málaque CMS: Acidente botrópico. In Animais Peçonhentos no Brasil: Biologia, Clínica e Terapêutica dos Acidentes. Edited by: Cardoso JLC, França FOS, Wen FH, Málaque CMS, Haddad V Jr. São Paulo: Sarvier/FAPESP; 2003:72-86.

29. Gutiérrez JM, Rucavado A, Escalante T, Díaz C: Hemorrhage induced by snake venom metalloproteinases: biochemical and biophysical mechanisms involved in microvessel damage. Toxicon 2005, 45:997-1011.

30. Gutiérrez JM, Ownby CL: Skeletal muscle degeneration induced by venom phospholipases $A_{2}$ : insights into the mechanisms of local and systemic myotoxicity. Toxicon 2003, 42:915-931.

31. Montecucco C, Gutiérrez JM, Lomonte B: Cellular pathology induced by snake venom phospholipase $A_{2}$ myotoxins and neurotoxins: common aspects of their mechanisms of action. Cell Mol Life Sci 2008, 65:2897-2912.

32. Campbell JA, Lamar WW: Venomous Reptiles of the Western Hemisphere Ithaca: Comstock Publishing Associates/Cornell University Press; 2004.

33. Fonseca F: Animais Peçonhentos São Paulo: Instituto Butantan; 1949.

34. Ribeiro LA, Jorge MT: Acidente por serpentes do gênero Bothrops: série de 3.139 casos. Rev Soc Bras Med Trop 1997, 30:475-480.

35. Ruiz de Torrent RM, Ulón SN, Sario HM: Epidemiológia del accidente ofídico en la provincia de Corrientes. Corrientes, Argentina: Universidad Nacional del Nordeste - Comunicaciones Científicas y Tecnológicas; 2004, Abstract V-029.

36. Bauab FA, Junqueira GR, Corradini MC, Silveira PV, Nishioka AS: Clinical and epidemiological aspects of the 'urutu' lance-headed viper (Bothrops alternatus) bite in a Brazilian hospital. Trop Med Parasitol 1994, 45:243-245.

37. Purtscher H, Burger M, Savio E, Juanicó LR, Domínguez BV, Caorsi E, Tambler M, Laborde A: Ofidismo y aracnidismo en el Uruguay. Diagnostico, complicaciones y tratamiento. Rev Med Uruguay 1983, 7:1-37.

38. Cardoso DF, Yamaguchi IK, Moura-da-Silva AM: Produção de soros antitoxinas e perspectivas de modernização por técnicas de biologia molecular. In Animais Peçonhentos no Brasil: Biologia, Clínica e Terapêutica dos Acidentes. Edited by: Cardoso JLC, França FOS, Wen FH, Málaque CMS, Haddad V Jr. São Paulo: Sarvier/FAPESP; 2003:367-379.

39. de Salud Ministerio: Resolución 34/2007 - Guia de prevención, diagnóstico, tratamiento y vigilancia epidemiológica de los envenenamientos ofídicos. Buenos Aires: Dirección de la Calidad de los Servicios de Salud, Ministerio da Salud; 2007.

40. Souza DH, lemma MR, Ferreira LL, Faria JP, Oliva ML, Zingali RB, Niewiarowski S, Selistre-de-Araujo HS: The disintegrin-like domain of the snake venom metalloprotease alternagin inhibits $\alpha_{2} \beta_{1}$ integrin-mediated cell adhesion. Arch Biochem Biophys 2000, 384:341-350.

41. Mariano-Oliveira A, Coelho AL, Terruggi CH, Selistre-de-Araujo HS, BarjaFidalgo $C$, de Freitas MS: Alternagin-C, a non-RGD-disintegrin, induces 
neutrophil migration via integrin signaling. Eur J Biochem 2003, 270:4799-4808

42. Cominetti MR, Ribeiro JU, Fox JW, Selistre-de-Araujo HS: BaG, a new dimeric metalloproteinase/disintegrin from the Bothrops alternatus snake venom that interacts with $a_{5} \beta_{1}$ integrin. Arch Biochem Biophys 2003, 416:171-179

43. Cominetti MR, Terruggi $\mathrm{CH}$, Ramos OH, Fox JW, Mariano-Oliveira A, De Freitas MS, Figueiredo CC, Morandi V, Selistre-de-Araujo HS: Alternagin-C, a disintegrin-like protein, induces vascular endothelial cell growth factor (VEGF) expression and endothelial cell proliferation in vitro. J Biol Chem 2004, 279:18247-18255.

44. Gay CC, Leiva LC, Maruñak S, Teibler P, Acosta de Pérez O: Proteolytic, edematogenic and myotoxic activities of a hemorrhagic metalloproteinase isolated from Bothrops alternatus venom. Toxicon 2005, 46:546-554.

45. Gay CC, Maruñak SL, Teibler P, Ruiz R, Acosta de Pérez OC, Leiva LC Systemic alterations induced by a Bothrops alternatus hemorrhagic metalloproteinase (baltergin) in mice. Toxicon 2009, 53:53-59.

46. Selistre-de-Araujo HS, Cominetti MR, Terruggi $\mathrm{CH}$, Mariano-Oliveira A, de Freitas MS, Crépin M, Figueiredo CC, Morandi V: Alternagin-C, a disintegrin-like protein from the venom of Bothrops alternatus, modulates $a_{2} \beta_{1}$ integrin-mediated cell adhesion, migration and proliferation. Braz J Med Biol Res 2005, 38:1505-1511.

47. Ramos OH, Terruggi CH, Ribeiro JU, Cominetti MR, Figueiredo CC, Bérard M, Crépin M, Morandi V, Selistre-de-Araujo HS: Modulation of in vitro and in vivo angiogenesis by alternagin- $C$, a disintegrin-like protein from Bothrops alternatus snake venom and by a peptide derived from its sequence. Arch Biochem Biophys 2007, 46:1-6.

48. Durigan JL, Peviani SM, Russo TL, Delfino GB, Ribeiro JU, Cominetti MR, Selistre-de-Araujo HS, Salvini TF: Effects of alternagin-C from Bothrops alternatus on gene expression and activity of metalloproteinases in regenerating skeletal muscle. Toxicon 2008, 52:687-694.

49. Ramos OH, Kauskot A, Cominetti MR, Bechyne I, Salla Pontes CL, Chareyre F, Manent J, Vassy R, Giovannini M, Legrand C, Selistre-de-Araujo HS, Crépin $M$, Bonnefoy $A$ : A novel $a_{v} \beta_{3}$-blocking disintegrin containing the RDG motive, DisBa-01, inhibits bFGF-induced angiogenesis and melanoma metastasis. Clin Exp Mestastasis 2008, 25:53-64.

50. Kauskot A, Cominetti MR, Ramos OH, Bechyne I, Renard JM, Hoylaerts MF, Crépin M, Legrand C, Selistre-de-Araujo HS, Bonnefoy A: Hemostatic effects of recombinant DisBa-01, a disintegrin from Bothrops alternatus. Front Biosci 2008, 13:6604-6616.

51. Nisenbom HE, Seki C, Vidal JC: Phospholipase $A_{2}$ from Bothrops alternatus (víbora de la cruz) venom. Purification and some characteristic properties. Toxicon 1986, 24:259-272.

52. Nisenbom HE, Perazzo JC, Monserrat AJ, Vidal JC: Contribution of phospholipase $A_{2}$ to the lethal potency of Bothrops alternatus (víbora de la cruz) venom. Toxicon 1986, 24:807-817.

53. Nisenbom HE, Perazzo JC, Monserrat AJ, Vidal JC: Effect of chemical modification with p-bromophenacyl bromide on the enzymatic and lethal properties of phospholipase $A_{2}$ from Bothrops alternatus (víbora de la cruz) venom. Toxicon 1988, 26:1137-1144.

54. Ponce-Soto LA, Lomonte B, Gutiérrez JM, Rodrigues-Simioni L, Novello JC, Marangoni S: Structural and functional properties of BaTX, a new Lys49 phospholipase $A_{2}$ homologue isolated from the venom of the snake Bothrops alternatus. Biochim Biophys Acta 2007, 1770:585-593.

55. Ponce-Soto $L A$, Barros JC, Marangoni S, Hernandez S, Dal Belo CA Corrado AP, Hyslop S, Rodrigues-Simioni L: Neuromuscular activity of BaTX, a presynaptic basic PLA 2 isolated from Bothrops alternatus snake venom. Comp Biochem Physiol C Toxicol Pharmacol 2009, 150:291-297.

56. Castro HC, Dutra DL, Oliveira-Carvalho AL, Zingali RB: Bothroalternin, a thrombin inhibitor from the venom of Bothrops alternatus. Toxicon 1998, 36:1903-1912.

57. Smolka MB, Marangoni S, Oliveira B, Novello JC: Purification and partial characterization of a thrombin-like enzyme, balterobin, from the venom of Bothrops alternatus. Toxicon 1998, 36:1059-1063.

58. Vitorino-Cardoso AF, Pereira Ramos OH, Homsi-Brandeburgo MI, Selistre-deAraujo HS: Insights into the substrate specificity of a novel snake venom serine peptidase by molecular modeling. Comp Biochem Physiol $B$ Biochem Mol Biol 2006, 144:334-342.

59. Stábeli RG, Marcussi S, Carlos GB, Pietro RC, Selistre-de-Araujo HS, Giglio JR, Oliveira EB, Soares AM: Platelet aggregation and antibacterial effects of an L-amino acid oxidase purified from Bothrops alternatus snake venom. Bioorg Med Chem 2004, 12:2881-2886.

60. Valério AA, Corradini AC, Panunto PC, Mello SM, Hyslop S: Purification and characterization of a phosphodiesterase from Bothrops alternatus snake venom. J Protein Chem 2002, 21:495-503.

61. Francischetti IMB, My-Pham V, Harrison J, Garfield MK, Ribeiro JMC: Bitis gabonica (gaboon viper) snake venom gland: toward a catalog of the full-length transcripts (cDNA) and proteins. Gene 2004, 337:55-69.

62. Wagstaff SC, Harrison RA: Venom gland EST analysis of the saw-scaled viper, Echis ocellatus, reveals novel $\alpha_{9} \beta_{1}$ integrin-binding motifs in venom metalloproteinases and a new group of putative toxins, reninlike aspartic proteases. Gene 2006, 377:21-32.

63. Kochva E: Oral glands of the Reptilia. In Biology of the Reptilia. Physiology B. Volume 8. Edited by: Gans C, Gans KA. London: Academic Press: 1978:43-161

64. Carneiro SM, Pinto VR, Jared C, Lula LA, Faria FP, Sesso A: Morphometric studies on venom secretory cells from Bothrops jararacussu (jararacuçu) before and after venom extraction. Toxicon 1991, 29:569-580.

65. Yamanouye N, Britto LR, Carneiro SM, Markus RP: Control of venom production and secretion by sympathetic outflow in the snake Bothrops jararaca. J Exp Biol 1997, 200:2457-2556.

66. Green P: PHRAP Documentation. University of Washington, Seattle; 1999 [http://bozeman.mbt.washington.edu/phrap.docs/phrap.html].

67. Baudet C, Dias Z: Analysis of slipped sequences in EST projects. Genet Mol Res 2006, 5:169-181.

68. Huang X, Madan A: CAP3: a DNA sequence assembly program. Genome Res 1999, 9:868-877.

69. Altschul SF, Madden TL, Schäffer AA, Zhang J, Zhang Z, Miller W, Lipman DJ: Gapped BLAST and PSI-BLAST: a new generation of protein database search programs. NuC Acids Res 1997, 25:3389-3402.

70. Ashburner M, Ball CA, Blake JA, Botstein D, Butler H, Cherry JM, Davis AP, Dolinski K, Dwight SS, Eppig JT, Harris MA, Hill DP, Issel-Tarver L, Kasarskis A, Lewis S, Matese JC, Richardson JE, Ringwald M, Rubin GM, Sherlock G: Gene ontology: tool for the unification of biology. The Gene Ontology Consortium. Nat Genet 2000, 25:25-29.

71. Thompson JD, Gibson TJ, Higgins DG: Multiple sequence alignment using ClustalW and ClustalX. Curr Protoc Bioinformatics 2002, 2:2.3.1-2.3.22.

72. Tang J, Vosman B, Voorrips RE, van der Linden CG, Leunissen JA: QualitySNP: a pipeline for detecting single nucleotide polymorphisms and insertions/deletions in EST data from diploid and polyploid species. BMC Bioinformatics 2006, 7:438.

73. Apweiler R, Bairoch A, Wu CH, Barker WC, Boeckmann B, Ferro S, Gasteiger E, Huang H, Lopez R, Magrane M, Martin MJ, Natale DA, O'Donovan C, Redaschi N, Yeh LS: UniProt: the Universal Protein knowledgebase. Nucleic Acids Res 2004, 32:D115-D119.

74. Jurka J, Kapitonov W, Pavlicek A, Klonowski P, Kohany O, Walichiewicz J: Repbase Update, a database of eukaryotic repetitive elements. Cytogenet Genom Res 2005, 110:462-467.

75. Rice P, Longden I, Bleasby A: EMBOSS: the European Molecular Biology Open Software Suite. Trends Genet 2000, 16:276-277.

76. Yamanouye N, Carneiro SM, Scrivano CN, Markus RP: Characterization of $\beta$ adrenoceptors responsible for venom production in the venom gland of the snake Bothrops jararaca. Life Sci 2000, 67:217-226.

77. Kerchove CM, Carneiro SM, Markus RP, Yamanouye N: Stimulation of the aadrenoceptor triggers the venom production cycle in the venom gland of Bothrops jararaca. J Exp Biol 2004, 207:411-416.

78. Kerchove CM, Luna MS, Zablith MB, Lazari MF, Smaili SS, Yamanouye N: $a_{1}{ }^{-}$ Adrenoceptors trigger the snake venom production cycle in secretory cells by activating phosphatidylinositol 4,5-bisphosphate hydrolysis and ERK signaling pathway. Comp Biochem Physiol A Mol Integr Physiol 2008, 150:431-437.

79. Borgheresi RA, Leroy JM, Yogi A, Dos Santos RA, Breno MC, Tostes RC: Pharmacologic and molecular characterization of the vascular $\mathrm{ET}_{\mathrm{A}}$ receptor in the venomous snake Bothrops jararaca. Exp Biol Med (Maywood) 2006, 231:729-735.

80. Junqueira-de-Azevedo IL, Pertinhez T, Spisni A, Carreño FR, Farah CS, Ho PL: Cloning and expression of calglandulin, a new EF-hand protein from the venom glands of Bothrops insularis snake in E. coli. Biochim Biophys Acta 2003, 1648:90-98. 
81. St. Pierre L, Woods R, Earl S, Masci PP, Lavin MF: Identification and analysis of venom gland-specific genes from the coastal taipan (Oxyranus scutellatus) and related species. Cell Mol Life Sci 2005, 62:2679-2693.

82. Jeffrey KL, Camps M, Rommel C, Mackay CR: Targeting dual-specificity phosphatases: manipulating MAP kinase signaling and immune responses. Nat Rev Drug Discov 2007, 6:391-403.

83. Goldbeter A, Pourquié O: Modeling the segmentation clock as a network of coupled oscillations in the Notch, Wnt and FGF signaling pathways. J Theor Biol 2008, 252:574-585.

84. Gomez C, Ozbudak EM, Wunderlich J, Baumann D, Lewis J, Pourquié O: Control of segment number in vertebrate embryos. Nature 2008, 454:335-339.

85. Arnér ES, Holmgren A: Physiological functions of thioredoxin and thioredoxin reductase. Eur J Biochem 2000, 267:6102-6109.

86. Arnér ES: Focus on mammalian thioredoxin reductases - important selenoproteins with versatile functions. Biochim Biophys Acta 2009, 1790:495-526.

87. Du XY, Clemetson KJ: Snake venom L-amino acid oxidase. Toxicon 2002 40:659-665.

88. Zuliani JP, Kayano AM, Zaqueo KD, Neto AC, Sampaio SV, Soares AM, Stábeli RG: Snake venom L-amino acid oxidases: some consideration about their functional characterization. Protein Pept Lett 2009, 16:908-912

89. Fox JW, Serrano SMT: Insights into and speculations about snake venom metalloproteinase (SVMP) synthesis, folding and disulfide bond formation and their contribution to venom complexity. FEBS J 2008 275:3016-3030.

90. Öhler M, Georgieva D, Seifert J, von Bergen M, Arni RK, Genov N, Betzel C The venomics of Bothrops alternatus is a pool of acidic proteins with predominant hemorrhagic and coagulopathic activities. J Proteome Res 2010, 9:2442-2437

91. Gallacci M, Cavalcante WLG: Understanding the in vitro neuromuscular activity of snake venom Lys49 phospholipase $A_{2}$ homologues. Toxicon 2010, 55:1-11.

92. Moura-da-Silva AM, Cardoso DF, Tanizaki MM: Differences in distribution of myotoxic proteins in venoms from different Bothrops species. Toxicon 1990, 28:1293-1301.

93. Moura-da-Silva AM, Desmond H, Laing G, Theakston RDG: Isolation and comparison of myotoxins isolated from venoms of different species of Bothrops snakes. Toxicon 1991, 29:713-723.

94. Moura-da-Silva AM, Cardoso DF, Tanizaki MM, Mota I: Neutralization of myotoxic activity of Bothrops venoms by antisera to purified myotoxins and to crude venoms. Toxicon 1991, 29:1471-1480.

95. Andrião-Escarso SH, Soares AM, Rodrigues VM, Angulo Y, Dias C, Lomonte B, Gutiérrez JM, Giglio JR: Myotoxic phospholipases $A_{2}$ in Bothrops snake venoms: effect of chemical modifications on the enzymatic and pharmacological properties of bothropstoxins from Bothrops jararacussu. Biochimie 2000, 82:755-763.

96. Tashima AK, Sanz L, Camargo ACM, Serrano SMT, Calvete JJ: Snake venomics of the Brazilian pitvipers Bothrops cotiara and Bothrops fonsecai. Identification of taxonomy markers. J Proteomics 2008, 71:473-485.

97. Correa-Netto C, Teixeira-Araujo R, Aguiar AS, Melgarejo AR, De-Simone SG, Soares MR, Foguel D, Zingali RB: Immunome and venome of Bothrops jararacussu: a proteomic approach to study the molecular immunology of snake toxins. Toxicon 2010, 55:1222-1235

98. Cogo JC, Lilla S, Souza GHMF, Hyslop S, de Nucci G: Purification, sequencing and structural analysis of two acidic phospholipases $A_{2}$ from the venom of Bothrops insularis (jararaca ilhoa). Biochimie 2006, 88:1947-1959.

99. Andrião-Escarso SH, Soares AM, Fontes MR, Fuly AL, Corrêa FM, Rosa JC, Greene $L$, Giglio JR: Structural and functional characterization of an acidic platelet aggregation inhibitor and hypotensive phospholipase $A_{2}$ from Bothrops jararacussu snake venom. Biochem Pharmacol 2002, 64:723-732.

100. Estevão-Costa MI, Rocha BC, Mudado MA, Redondo R, Franco GR, FortesDias CL: Prospection, structural analysis and phylogenetic relationships of endogenous $\mathrm{Y}$-phospholipase $\mathrm{A}_{2}$ inhibitors in Brazilian Bothrops snakes (Viperidae, Crotalinae). Toxicon 2008, 52:122-129.

101. Zaganelli GL, Zaganelli MG, Magalhães A, Diniz CR, de Lima ME: Purification and characterization of a fibrinogen-clotting enzyme from the venom of jararacuçu (Bothrops jararacussu). Toxicon 1996, 34:807-819.
102. Serrano SM, Hagiwara Y, Murayama N, Higuchi S, Mentele R, Sampaio CA, Camargo AC, Fink E: Purification and characterization of a kinin-releasing and fibrinogen-clotting serine proteinase (KN-BJ) from the venom of Bothrops jararaca, and molecular cloning and sequence analysis of its cDNA. Eur J Biochem 1998, 251:845-853.

103. Fox JW, Ma L, Nelson K, Sherman NE, Serrano SMT: Comparison of indirect and direct approaches using ion-trap and Fourier transform ion cyclotron resonance mass spectrometry for exploring viperid venom proteomes. Toxicon 2006, 47:700-714.

104. Zingali RB, Jandrot-Perrus $M$, Guillin M, Bon C: Bothrojaracin, a new thrombin inhibitor isolated from Bothrops jararaca venom: characterization and mechanism of thrombin inhibition. Biochemistry 1993, 32:10794-10802.

105. Arocas V, Zingali RB, Guillin MC, Bon C, Jandrot-Perrus M: Bothrojaracin: a potent two-site-directed thrombin inhibitor. Biochemistry 1996, 35:9083-9089.

106. Ferreira SH: A bradykinin-potentiating factor (BPF) present in the venom of Bothrops jararaca. Br J Pharmacol Chemother 1965, 24:163-169.

107. Menin L, Perchuć A, Favreau P, Perret F, Michalet S, Schöni R, Wilmer M, Stöcklin R: High throughput screening of bradykinin-potentiating peptides in Bothrops moojeni snake venom using precursor ion mass spectrometry. Toxicon 2008, 51:1288-1302

108. Murayama N, Hayashi MA, Ohi H, Ferreira LA, Hermann W, Saito H, Fujita Y, Higuchi S, Fernandes BL, Yamane T, de Camargo AC: Cloning and sequence analysis of a Bothrops jararaca cDNA encoding a precursor of seven bradykinin-potentiating peptides and a C-type natriuretic peptide. Proc Natl Acad Sci USA 1997, 94:1189-1193.

109. Higuchi S, Murayama N, Saguchi K, Ohi H, Fujita Y, Camargo AC, Ogawa T, Deshimaru M, Ohno M: Bradykinin-potentiating peptides and C-type natriuretic peptides from snake venom. Immunopharmacology 1999, 44:129-135.

110. Núñez $V$, Cid $P$, Zanz $L$, de la Torre $P$, Angulo $Y$, Lomonte $B$, Gutiérrez JM, Calvete JJ: Snake venomics and antivenomics of Bothrops atrox venoms from Colombia and the Amazonian regions of Brazil, Perú and Ecuador suggest the occurrence of geographic variation of venom phenotype by a trend towards paedomorphism. J Proteomics 2009, 73:57-78.

111. Soares MR, Oliveira-Carvalho AL, Wermelinger LS, Zingali RB, Ho PL, Junqueira-de-Azevedo IL, Diniz MRV: Identification of novel bradykininpotentiating peptides and C-type natriuretic peptide from Lachesis muta venom. Toxicon 2005, 46:31-38.

112. Alape-Girón A, Sanz L, Escolano J, Flores-Díaz M, Madrigal M, Sasa M, Calvete JJ: Snake venomics of the lancehead pitviper Bothrops asper: geographic, individual, and ontogentic variation. J Proteome Res 2008, 7:3556-3571.

113. Alape-Girón A, Flores-Díaz M, Sanz L, Madrigal M, Escolano J, Sasa M, Calvete JJ: Studies on the venom proteome of Bothrops asper: perspectives and applications. Toxicon 2009, 54:938-948.

114. Peichoto ME, Mackessy SP, Teibler P, Tavares FL, Burckhardt PL, Breno MC, Acosta O, Santoro ML: Purification and characterization of a cysteine-rich protein from Philodryas patagoniensis snake venom. Comp Biochem Physiol C Toxicol Pharmacol 2009, 150:79-84.

115. Aird SD: Snake venom dipeptidyl peptidase IV: taxonomic distribution and quantitative variation. Comp Biochem Physiol B Biochem Mol Biol 2008, 150:222-228.

116. Ogawa Y, Mamura Y, Murayama N, Yanoshita R: Characterization and cDNA cloning of dipeptidyl peptidase IV from the venom of Gloydius blomhoffi brevicaudus. Comp Biochem Physiol B Biochem Mol Biol 2006, 145:35-42.

117. Gasparello-Clemente E, Silveira PF: Fluorometric assay using naphthylamide substrates for assessing novel venom peptidase activities. Toxicon 2002, 40:1617-1626.

118. Ogawa Y, Kanai-Azuma M, Akimoto Y, Kawakami H, Yanoshita R: Exosomelike vesicles in Gloydius blomhoffii blomhoffii venom. Toxicon 2008, 51:984-993.

119. Aird SD: Ophidian envenomation strategies and the role of purines. Toxicon 2002, 40:335-393.

120. Kreil G, Haiml L, Suchanek G: Stepwise cleavage of the pro part of promelittin by dipeptidylpeptidase IV. Evidence for a new type of precursor-product conversion. Eur J Biochem 1980, 111:49-58.

121. Lee VA, Tu WC, Jinn TR, Peng CC, Lin LJ, Tzen JT: Molecular cloning of the precursor polypeptide of mastoparan $B$ and its putative processing 
enzyme, dipeptidyl peptidase IV, from the black-bellied hornet, Vespa basilis. Insect Mol Biol 2007, 16:231-237.

122. Junqueira-de-Azevedo IL, Farsky SH, Oliveira ML, Ho PL: Molecular cloning and expression of a functional snake venom vascular endothelium growth factor (VEGF) from the Bothrops insularis pit viper. A new member of the VEGF family of proteins. J Biol Chem 2001, 276:39836-39842.

123. Queiroz GP, Pessoa LA, Portaro FC, Furtado MF, Tambourgi DV: Interspecific variation in venom composition and toxicity of Brazilian snakes from Bothrops genus. Toxicon 2008, 52:842-851.

124. Pessatti M, Fontana JD, Furtado MF, Guimãraes MF, Zanette $L R$, Costa WT, Baron M: Screening of Bothrops snake venoms for L-amino acid oxidase activity. Appl Biochem Biotechnol 1995, 51-52:197-210.

125. Nascimento JM, Franchi GC Jr, Nowill AE, Collares-Buzato CB, Hyslop S: Cytoskeletal rearrangement and cell death induced by Bothrops alternatus snake venom in cultured Madin-Darby canine kidney cells. Biochem Cell Biol 2007, 85:591-605.

126. Fry BG, Wüster W, Kini RM, Brusic V, Khan A, Venkataraman D, Rooney AP: Molecular evolution and phylogeny of elapid snake venom three-finger toxins. J Mol Evol 2003, 57:110-129.

127. Fry BG, Scheib H, van der Weerd L, Young B, McNaughtan J, Ramjan SF, Vidal N, Poelmann RE, Norman JA: Evolution of an arsenal: structural and functional diversification of the venom system in the advanced snakes (Caenophidia). Mol Cell Proteomics 2008, 7:215-246.

128. Pahari S, Mackessy SP, Kini RM: The venom gland transcriptome of the dessert massasauga rattlesnake (Sistrurus catenatus edwardsii): towards an understanding of venom composition among advanced snakes (Superfamily Colubroidea). BMC Mol Biol 2007, 8:115.

129. Pawlak J, Kini RM: Unique gene organization of colubrid three-finger toxins: complete CDNA and gene sequences of denmotoxin, a birdspecific toxin from colubrid snake Boiga dendrophila (mangrove catsnake). Biochimie 2008, 90:868-877.

130. Pawlak J, Mackessy SP, Sixberry NM, Stura EA, Le Du MH, Ménez R, Foo CS, Ménez A, Nirthanan S, Kini RM: Irditoxin, a novel covalently linked heterodimeric three-finger toxin with high taxon-specific neurotoxicity. FASEB J 2009, 23:534-545.

131. Angulo Y, Escolano J, Lomonte B, Gutiérrez JM, Sanz L, Calvete JJ: Snake venomics of Central American pitvipers: clues for rationalizing the distinct envenomation profiles of Atropoides nummifer and Atropoides picadoi. J Proteome Res 2008, 7:708-719.

132. Jia Y, Cantu BA, Sánchez EE, Pérez JC: Complementary DNA sequencing and identification of mRNAs from the venomous gland of Agkistrodon piscivorus leucostoma. Toxicon 2008, 51:1457-1466.

133. Qinghua L, Xiaowei Z, Wei Y, Chenji L, Yijun H, Pengxin Q, Wingwen S, Songnian $\mathrm{H}$, Guangmei Y: A catalog for transcripts in the venom gland of the Agkistrodon acutus: identification of the toxins potentially involved in coagulopathy. Biochem Biophys Res Commun 2006, 341:522-531.

134. Zhang B, Liu Q, Yin W, Zhang X, Huang Y, Luo Y, Qiu P, Su X, Yu J, Hu S, Yan G: Transcriptome analysis of Deinagkistrodon acutus venomous gland focusing on cellular structures and functional aspects using expressed sequence tags. BMC Genomics 2006, 7:152.

135. Casewell NR, Harrison RA, Wüster W, Wagstaff SC: Comparative venom gland transcriptome surveys of the saw-scaled vipers (Viperidae: Echis) reveal substantial intra-family gene diversity and novel venom transcripts. BMC Genomics 2009, 30:564.

136. Sanz L, Gibbs HL, Mackessy SP, Calvete JJ: Venom proteomes of closely related Sistrurus rattlesnakes with divergent diets. J Proteome Res 2006, 5:2098-2112.

137. Guércio AP, Shevchenko A, Shevchenko A, López-Lozano JL, Paba J, Sousa MV, Ricart CAO: Ontogenetic variations in the venom proteome of the Amazonian snake Bothrops atrox. Proteome Sci 2006, 4:11.

138. Zamunér SR, Cruz-Höfling MA, Corrado AP, Hyslop S, Rodrigues-Simioni L: Comparison of the neurotoxic and myotoxic effects of Brazilian Bothrops venoms and their neutralization by commercial antivenom. Toxicon 2004, 44:259-271.

139. Pung YF, Wong PT, Kumar PP, Hodgson WE, Kini RM: Ohanin, a novel protein from king cobra venom, induces hypolocomotion and hyperalgesia in mice. J Biol Chem 2005, 280:13137-13147.

140. Pung YF, Kumar SV, Rajagopalan N, Fry BG, Kumar PP, Kini RM: Ohanin, a novel protein from king cobra venom and its CDNA and genomic organization. Gene 2006, 371:246-256.
141. Birrell GW, Early STH, Wallis TP, Masci PP, de Jersey J, Gorman JJ, Lavin MF: The diversity of bioactive proteins in Australian snake venoms. Mol Cell Proteomics 2007, 6:973-986.

142. Brown AM, Yatani A, Lacerda AE, Gurrola GB, Possani LD: Neurotoxins that act selectively on voltage-dependent cardiac calcium channels. Circ Res 1987, 61:16-19.

143. Possani LD, Martin BM, Yatani A, Mochca-Morales J, Zamudio FZ, Gurrola GB, Brown AM: Isolation and physiological characterization of taicatoxin, a complex toxin with specific effects on calcium channels. Toxicon 1992, 30:1343-1364

144. Fantini E, Athias P, Tirosh R, Pinson A: Effect of TaiCatoxin (TCX) on the electrophysiological, mechanical and biochemical characteristics of spontaneously beating ventricular cardiomyocytes. Mol Cell Biochem 1996, 160-161:61-66.

145. Sales PBV, Santoro ML: Nucleotidase and DNase activities in Brazilian snake venom. Comp Biochem Physiol C 2008, 147:85-95.

146. Ogawa $Y$, Murayama N, Yanoshita R: Molecular cloning and characterization of ecto-5'-nucleotidase from the venoms of Gloydius blomhoffi. Toxicon 2009, 54:408-412.

147. Ohno M, Chijiwa T, Oda-Ueda N, Ogawa T, Hattori S: Molecular evolution of myotoxic phospholipases $A_{2}$ from snake venom. Toxicon 2003, 42:841-854.

148. Soto JG, Powell RL, Reyes SR, Wolana L, Swanson LJ, Sanchez EE, Perez JC: Genetic variation of a disintegrin gene found in the American copperhead snake (Agkistrodon contortrix). Gene 2006, 373:1-7.

149. Kordis D, Gubenšek F: Bov-B long interspersed repeated DNA (LINE) sequences are present in Vipera ammodytes phospholipase $A_{2}$ genes and in genomes of Viperidae snakes. Eur J Biochem 1997, 246:772-779.

150. Kordis $D$, Gubenšek F: The Bov-B lines found in Vipera ammodytes toxic $\mathrm{PLA}_{2}$ genes are widespread in snake genomes. Toxicon 1998, 36:1585-1590.

doi:10.1186/1471-2164-11-605

Cite this article as: Cardoso et al:: A transcriptomic analysis of gene expression in the venom gland of the snake Bothrops alternatus (urutu). BMC Genomics 2010 11:605.

\section{Submit your next manuscript to BioMed Central and take full advantage of:}

- Convenient online submission

- Thorough peer review

- No space constraints or color figure charges

- Immediate publication on acceptance

- Inclusion in PubMed, CAS, Scopus and Google Scholar

- Research which is freely available for redistribution

Submit your manuscript at www.biomedcentral.com/submit
Biomed Central 